\title{
GRAS-FED AMERICANS: SICK OF LAX REGULATION OF FOOD ADDITIVES
}

\author{
Martha Dragich*
}

\section{INTRODUCTION}

Food in America today is largely processed, packaged, and laden with additives. Many processed foods are carefully engineered to hit the "bliss point" of flavor, texture, and mouthfeel at which consumers become unable to resist them. ${ }^{1}$ Food products are also engineered to eliminate fat, sugar, gluten, or other nutrients thought to be undesirable. ${ }^{2}$ These nutrients are often replaced with synthetic substitutes necessary to give the product a familiar shape, texture, flavor, or shelf-life. ${ }^{3}$ For these reasons, processed and packaged food products typically contain a large number of ingredients, many unfamiliar as foods. ${ }^{4}$ Many people wonder about their safety, particularly over the long term, amid a barrage of news reports about how food products can interfere with health. ${ }^{5}$

Though Americans generally assume that the federal Food \& Drug Administration ("FDA") oversees the food supply and ensures its safety, ${ }^{6}$ the fact is that most food is regulated only on a post-market basis - meaning that the FDA becomes aware of and responds to food safety issues only after a problem has developed. ${ }^{7}$ This is so because the governing statute, the Food Drug and

* James S. Rollins Professor of Law University of Missouri-Columbia. B.A., University of Minnesota, 1978; J.D., M.A., University of Minnesota, 1983; L.L.M., University of Arkansas, 2012). The author is grateful to the librarians and staff of the University of Missouri Law Library for their assistance, and to the University of Missouri Law Foundation for research support.

1. Michael Moss, Salt Sugar Fat, at xvii-xix (Random House 2013).

2. Id. at 20 .

3. Id. at 68 .

4. Id. at 71 .

5. Id. at 39 .

6. See generally James T. O'Reilly, Are We Cutting the GRAS? Food Safety Perceptions Are Diminished by Dysfunctional Bureaucratic Silos, 59 Food \& Drug L.J. 417, 417 (2004) (discussing developments "undercutting the historic foundations of [FDA] credibility" regarding the safety of the U.S. food supply); Gen. Accounting OfFice, FDA SHOuld Strengthen its Oversight of Food Ingredients Determined to Be Generally ReCOGNIZED AS SAFE (GRAS) 33 (2010) (noting that a growing number of substances are "effectively excluded from federal oversight").

7. This Article focuses on foods under the jurisdiction of the FDA. According to a recent report, the FDA has regulatory responsibility for about eighty percent of the current U.S. food supply. Nicole E. Negowetti, Food Labeling Litigation: Exposing Gaps in the FDA's RESOURCES AND REgUlATORY AUTHORITy 2 (2014), available at http://www.brookings.edu/ /media/research/files/papers/2014/06/26-food-labeling-litigation/negowetti_food-labelinglitigation.pdf [http://perma.cc/3G3P-KZ2B]. Other foods-most notably meat and poultry and foods containing these ingredients, and in some cases eggs — come under the jurisdiction of the U.S. Department of Agriculture (USDA). The regime for USDA-regulated foods differs in important 
Cosmetic Act of 1938 ("FDCA"), is premised on a view of food as whole, raw commodities, often purchased from known local suppliers and prepared at home, the safety of which consumers were able to evaluate for themselves. ${ }^{8}$ By the 1950 s, the food supply had begun to shift markedly towards industriallyproduced foods that often contain chemical or synthetic additives unknown to home cooks. ${ }^{9}$ Consumers generally know little about where these food products originate, what is in them, or how they were produced..$^{10}$ Packaging often precludes a consumer's own sensory evaluation of the food product. Many products containing additives that do not occur naturally are labeled and marketed as "all natural." "Such labeling may confuse consumers or cause them not to read the ingredient list and investigate the substances found there.

The FDCA presumes that food is safe until proven otherwise. ${ }^{12}$ The statute holds producers responsible for the safety of their produce, but imposes no premarket inspection regime for foods it covers. ${ }^{13}$ The most common safety problems of traditional foods are contamination with pathogens or toxins. ${ }^{14}$ These conditions generally lead to outbreaks of acute illnesses that, though often serious and capable of causing death, are usually treatable. ${ }^{15}$

Under the FDCA's broad definition of food, the FDA's jurisdiction

respects from that of FDA foods, particularly in that it requires both pre-market inspection of products and pre-approval of labeling. See Federal Meat Inspection Act, 21 U.S.C. $\S \S 601-695$ (2012); Poultry Products Inspection Act, 21 U.S.C. $\S \S 451-472$ (2012); Egg Products Inspection Act, 21 U.S.C. $\S \S 1031-1056$ (2012).

8. Food Drug and Cosmetic Act of 1938, Pub. L. No. 75-717, 52 Stat. 1040.

9. According to one scholar,

Before World War II there were relatively few food additives for functional purposes.

The revolution in food technology in the 1940s and 1950s brought a proliferation of

new additives. Moreover, changes in demographics, particularly the migration of the population from farms to the cities, fueled a growing need for additives, such as preservatives.

Neal D. Fortin, Food Regulation: Law, Science, Policy, and Practice 261 (John Wiley \& Sons, Inc. 2009).

10. See generally id.

11. Food Labeled 'Natural' May Not Be, Consumer Advocates Warn, N.Y. DAILY News (Feb. 10, 2014), http://www.nydailynews.com/life-style/health/foods-labeled-natural-not-consumeradvocates-warn-article-1.1608355 [http://perma.cc/234K-LRJD].

12. 21 U.S.C. $\$ 348$ (a) (2012).

13. Id.

14. See generally Gen. AcCounting OfFice, supra note 6, at 3 (discussing test protocols for evaluation of acute as opposed to chronic conditions).

15. See Foodborne Germs and Illnesses, Ctrs. for Disease Control \& Prevention, http://www.cdc.gov/foodsafety/facts.html [http://perma.cc/DQ4V-YNEA] (last updated Sept. 24, 2015) (describing symptoms of foodborne illness); Estimates of Foodborne Illness in the United States, Ctrs. FOR DiseAse Control \& Prevention, http://www.cdc.gov/foodborneburden [http://perma.cc/ZN5U-VCNT] (last updated Sept. 8, 2014) (reporting roughly forty-eight million cases of foodborne illness per year, 128,000 hospitalizations, and 3000 deaths). 
encompasses the highly processed, packaged foods widely available today. ${ }^{16}$ Chemical additives in processed foods are likely to present very different kinds of safety problems from the acute illnesses caused by contaminated traditional foods. ${ }^{17}$ Additives, often used in small amounts in a plethora of products consumed over a lifetime, are apt to contribute to the development of chronic conditions and diseases that take their toll gradually. ${ }^{18}$ Even consumers who diligently read labels to determine which additives are contained in their food will find themselves unable to evaluate these dangers at the point of purchase or consumption.

Congress responded to these dangers by enacting the Food Additives Amendment of 1958, which established a different, much stricter regime for the regulation of food additives. ${ }^{19}$ Briefly put, food containing additives is deemed unsafe unless the safety of the additive has been established before the food comes to market. ${ }^{20}$ Without pre-market approval, sale of such food in interstate commerce is unlawful. ${ }^{21}$ Implementation of this regulatory scheme was entrusted to the Food \& Drug Administration ("FDA"). ${ }^{22}$

The FDA, however, is not exercising the statutorily-mandated oversight of food additives or applying the safety standards Congress outlined. Most additives entering the market since 1970 have done so based upon producer or industry self-determinations of safety rather than by FDA evaluation and approval. ${ }^{23}$ Of approximately ten thousand additives reputed to be in the food supply, some three thousand have reportedly never been reviewed for safety by the FDA. ${ }^{24}$ The FDA has woefully incomplete information about food additives in use today. It is estimated that for at least one thousand additives currently in use in food, the FDA has no information whatsoever. ${ }^{25}$ Even when the FDA has been notified of

16. See 21 U.S.C. $\S 321(\mathrm{f})$.

17. Compare Peter Lehner, Food Additives 'Generally Recognized as Safe' Could Be Anything But, LIVE SCI. (Apr. 25, 2014), http://www.livescience.com/45127-food-additiveconcerns.html [http://perma.cc/XP9N-RBXK], with Be Food Safe: Protect Yourself from Food Poisoning, Ctrs. For Disease Control \& Prevention, http://www.cdc.gov/features/befoodsafe/ [http://perma.cc/T22W-9PAE] (last updated May 6, 2013).

18. Gen. Accounting OfFice, supra note 6, at 2.

19. See Food Additives Amendment of 1958, Pub. L. No. 85-929, 72 Stat. 1784 (codified as amended in scattered sections of 21 U.S.C.).

20. 21 U.S.C. $\S 348$.

21. Id.

22. Id. $\S 341$.

23. Peter Barton Hutt \& Richard A. Merrill, Food \& Drug law: Cases and MATERIALs 428 (3d ed. 2007).

24. Pew Charitable Trs., Fixing the Oversight of Chemicals Added to Our Food 5 (2013), available at http://www.pewtrusts.org/en/research-and-analysis/reports/2013/11/07/ fixingthe-oversight-of-chemicals-added-to-our-food [http://perma.cc/L8FS-BDYC].

25. Complaint for Declaratory and Injunctive Relief at 16, Ctr. for Food Safety v. Burwell, 1:14-cv-00267-RC (D.D.C. Sept. 4, 2015), 2014 WL 1392926 [hereinafter Ctr. for Food Safety Complaint] (describing the effect of manufacturers' self-determinations of GRAS without 
a producer's determination of safety for a particular use of an additive, other uses of the additive may be occurring without the FDA's knowledge. ${ }^{26}$ In that event, the FDA is unable to assess statutorily-mandated safety factors relating to cumulative exposure to additives across the typical diet over the lifetime of an American. ${ }^{27}$

Agency inattention and consumer ignorance may be attributed to the fact that additives in use today, even if unsafe, are likely to present or exacerbate problems of chronic illness rather than the acute illnesses resulting from ingesting food contaminated with pathogens or foreign objects. Causation of long-term health problems and chronic diseases is often attenuated and evidence of causation accumulates slowly. Consumers appreciate the lower cost, higher convenience, shelf stability, and other characteristics that food additives make possible. ${ }^{28}$ The rising incidence of obesity and related diseases makes consumers eager to accept miracle food products containing non-digestible fats, non-caloric sweeteners, and other substitutes for the dietary villains of the moment. ${ }^{29}$

But recent events have begun to suggest that agency indifference and consumer acceptance regarding food additives may be misplaced. Most notably, the FDA has just announced that trans fats, formerly treated as "generally recognized as safe" ("GRAS") substances, are not safe at any level. ${ }^{30}$ Accordingly, GRAS status has been revoked on the basis of new information. Producers have three years to remove trans fats from the food supply. ${ }^{31}$ Any future use would have to be permitted under a full-blown food additive regulation. ${ }^{32}$ The non-digestible fat, Olestra, was originally approved as safe for certain uses under a food additive petition, subject to a warning statement on the

notification to the FDA).

26. Gen. Accounting OfFice, supra note 6, at 12.

27. Id. at 13 .

28. Food Additives, Kan. ST. U., http://www.k-state.edu/kvafl/ingredients/additives.html [http://perma.cc/3KLA-R7H3] (last updated June 18, 2015) (noting food additives help preserve and enrich food, improve its color and flavor, and can make food processing easier).

29. See, e.g., Artificial Sweeteners, Harv. U. Sch. Pub. Health, http://www.hsph.harvard. edu/nutritionsource/healthy-drinks/artificial-sweeteners/ [http://perma.cc/QV5Q-H625] (last visited Nov. 15, 2015) (noting various studies addressing obesity and artificial sweeteners).

30. News Release, Food \& Drug Admin., The FDA Takes Steps to Remove Artificial Trans Fats in Processed Foods (June 16, 2015), available at http://www.fda.gov/NewsEvents/ Newsroom/PressAnnouncements/ucm451237.htm [http://perma.cc/PEE2-VMVM] (stating that trans fats are no longer GRAS).

31. See Artificial Sweeteners and Cancer, NAT'L CANCER INST., http://www.cancer.gov/ about-cancer/causes-prevention/risk/diet/artificial-sweeteners-fact-sheet [http://perma.cc/5CYU5E98] (last visited Nov. 15, 2015).

32. If not GRAS, trans fats could be used in food only under the terms of a food additive regulation limiting the amount and conditions of use. 21 U.S.C. $§ 348(c)(1)(A)(2012)$. If there is no safe level of use, a food additive regulation may not be issued and the substance may not be used in food. Id. $\S 348(\mathrm{a})(2)$. 
label. ${ }^{33}$ The warning requirement was later dropped despite a large number of adverse reaction reports. ${ }^{34}$ The use of Olestra has since expanded to products outside the original approval as a result of GRAS notifications to the FDA. ${ }^{35}$ Artificial sweeteners including saccharine, cyclamate, and aspartame have convoluted histories in the FDA approval process. ${ }^{36}$ In the cases of saccharine and cyclamate, well-publicized studies led to a media frenzy that eventually spurred the FDA to reverse its position, but these actions affected only a handful of the approximately ten thousand additives in use in the food supply. There is some evidence calling into question the safety of many other additives. ${ }^{37} \mathrm{~A}$ recent citizen petition requested that the FDA ban the use of eight artificial flavorings, all of which have been in use for decades, permitted under a food additive regulation or as GRAS. ${ }^{38}$ A recent report challenged the safety of several emulsifiers in common use. ${ }^{39}$ Petitions seeking FDA review of such substances often languish for years. ${ }^{40}$

Moreover, the FDA twice loosened the requirements of the premarket review process for food additives. Producers and industry groups are allowed to "selfdetermine" the GRAS status of additives they wish to use. ${ }^{41}$ Since 1997, the FDA has been operating under a Proposed Rule under which additive proponents submit only summary information about safety. ${ }^{42}$ Notification to the FDA is voluntary $;{ }^{43}$ FDA approval is no longer a stop on the road to market for most additives. Recent litigation over this procedure culminated in a consent decree requiring the FDA to finalize its Proposed Rule by August 2016, ${ }^{44}$ but does not

33. See Marion Nestle, The Selling of Olestra, 133 Pub. Health Rep. 508, 509 (1998) (noting the oddity of a finding of safety coupled with a strong required warning as to ill effects); see also The Facts About Olestra, CTR. FOR SCI. PUB. INT., www.cspinet.org/olestra/history.html [http://perma.cc/7ZN7-E6M3] (last visited Nov. 15, 2015).

34. Ctr. for Food Safety Complaint, supra note 25, at 3.

35. Id.

36. See Hutt \& Merrill, supra note 23, at 403-04.

37. See Kimberly Kindy, Food Additives on the Rise as FDA Scrutiny Wanes, WASH. Post (Aug. 17, 2014), https://www.washingtonpost.com/national/food-additives-on-the-rise-as-fdascrutiny-wanes/2014/08/17/828e9bf8-1cb2-11e4-ab7b-696c295ddfd1_story.html [http://perma.cc/KRP8-X36P].

38. FDA Food Ingredient Approval Process Violates Law, Says CSPI, CTR. FOR SCI. PuB. INT. (Apr. 15, 2015), http://cspinet.org/new/201504151.html [http://perma.cc/NT6C-NPNV].

39. See, e.g., Cornucopia Inst., CarageEnan: How a "NAtural" Food AdDitive is MAKING US SicK 11-12 (2013), available at $\mathrm{http}: / / \mathrm{www}$. cornucopia.org/wp-content/uploads/2013/ 02/Carrageenan-Report1.pdf [http://perma.cc/5DZ3-ZQ5K].

40. Ctr. for Food Safety Complaint, supra note 25, at 13.

41. See Substances Generally Recognized as Safe, 62 Fed. Reg. 18,938-01 (proposed Apr. 17, 1997) (to be codified at 21 C.F.R. pt. 170).

42. $I d$.

43. Id.

44. Consent Decree, Ctr. for Food Safety v. Burwell, 1:14-cv-00267-RC (D.D.C. Sept. 4, 2015) [hereinafter Consent Decree]. 
require substantive changes to the notification procedure. By its own account, "[o]ne of FDA's core regulatory functions is ensuring that food, including all substances added to food, is safe." ${ }^{45}$ It is disconcerting that the FDA's oversight of food additives never achieved the robustness Congress had in mind and has steadily declined in the decades since enactment of the Food Additives Amendment.

What can be done to restore a measure of oversight of food additives? Major reform does not look promising. The conventional narrative holds that the FDA is overworked, understaffed, and underfunded. No one expects that situation to change significantly because that would require political will that appears to be lacking. Expanding the role of administrative agencies, and providing funding to support it, is decidedly out of favor. Congress rarely turns its attention to the regulation of food and, having passed the FDA Food Safety Modernization Act ("FSMA") in $2010,{ }^{46}$ is unlikely in the near future to consider an overhaul of food additive provisions. FSMA itself is evidence of Congress' greater willingness to respond to outbreaks (or threats) of acute foodborne illness than to consider long-term consequences of diet leading to chronic diseases. ${ }^{47}$ For these reasons, proposals to return to the full pre-market approval regime outlined in the 1958 Act would fall on deaf ears.

Others have written in detail about how this oversight process has broken down and have suggested a variety of ways to address the problem of providing a sufficiently robust oversight process within the constraints of the FDA's budget, staffing, and priorities. ${ }^{48}$ This Article focuses not on the FDA's administrative process but rather on substantive duties of producers that, if adopted or reinvigorated, would provide a base of information that would allow for more agile FDA response when safety concerns develop.

This Article proposes several modest steps that, taken together, would improve oversight where it is needed most. These reforms fall into three broad categories: drawing the line between food additives, GRAS substances, and food in an appropriate place for purposes of regulatory treatment; compiling complete and accurate information about additives currently in the food supply and monitoring their safety; and addressing the use of the misleading term "natural" on the labeling of foods containing additives. More specifically, definitions that

45. Final Determination Regarding Partially Hydrogenated Oils (Removing Trans Fat), FOOD \& DRUG ADMIN., http://www.fda.gov/food/ingredientspackaginglabeling/foodadditives ingredients/ucm449162.htm [http://perma.cc/74E5-XL5M] (last updated June 18, 2015).

46. See Food Safety Modernization Act, Pub. L. No. 111-353, 124 Stat. 3885 (2011) (codified as amended in scattered sections of 21 U.S.C.).

47. The FSMA adopted the Hazard Analysis and Critical Control Point (HACCP) approach to food safety, which stresses prevention of outbreaks by continuous monitoring and documentation of farm or factory conditions. See ForTIN, supra note 9, at 240-45 (discussing HACCP and foodborne illness). But the focus remains on preventing acute foodborne illness rather than on addressing chronic health problems. $I d$.

48. See, e.g., Lars Noah \& Richard A. Merrill, Starting from Scratch?: Reinventing the Food Additive Approval Process, 78 B.U. L. ReV. 329, 429-43 (1998). 
are the key to the FDCA's scheme should be amended. First, the definition of "food additives" should be revised to eliminate overlap with that of "food" and to re-establish that these different substances receive distinct regulatory treatment. The definition of "safe" substances for use in food should explicitly take account of long-term health concerns and chronic diseases. Some of these definitional changes may require congressional action; others may be accomplished by the FDA under its delegated power to enforce the FDCA.

Moving beyond definitions, certain aspects of the regulatory process must be strengthened. Producers should be required to notify the FDA of all additives in use and provide information about their safety to ensure that there is a complete inventory of additives in use in our food supply. The obligations of producers to monitor safety on an ongoing basis should be made clear. The statute should be amended to impose a duty on the part of producers to report to the FDA credible new information regarding the safety of an additive that might serve as the basis for revising the conditions of use or revoking GRAS status altogether. The FDA's authority to do so is clear under existing law. Finally, products containing additives as redefined should not be permitted to be labeled as "natural."

To set the stage for this discussion, this Article turns first to a brief history of the regulation of food additives.

\section{History of Food Additives Regulation}

The history of food safety legislation, from the Federal Food and Drugs Act of 1906 through the FSMA in 2010, displays a consistent focus on safety, health, and fair dealing in the U.S. food system. The FDA's website states that the FDA "protects the public health by assuring ... the safety and security of our nation's food supply. ${ }^{49}$ A June 2015 blog post by Dr. Susan Mayne, Director of the FDA's Center for Food Safety and Applied Nutrition stated:

At the heart of FDA's mission is a responsibility to ensure that the foods we eat, and share with our family, are as safe as possible. It's a responsibility to protect health by taking action when needed, based on the best available science. This action will ultimately allow all of us to enjoy safer foods and healthier lives. ${ }^{50}$

As noted above, new additives and new technologies are an important area of concern. This concern dates back to the mid-twentieth century when the food supply was in transition from mostly whole foods to industrially-produced packaged and processed foods..$^{51}$

49. Press Release, Food \& Drug Admin., FDA Takes Step to Further Reduce Trans Fats in Processed Foods (Nov. 9, 2013), available at http://www.fda.gov/NewsEvents/Newsroom/ PressAnnouncements/ucm373939.htm [http://perma.cc/9GQH-GHHZ].

50. Susan Mayne, Protecting Consumers from Trans Fat, Food \& DRUG Admin. (June 15, 2015), http://blogs.fda.gov/fdavoice/index.php/2015/06/protecting-consumers-from-trans-fat/ [http://perma.cc/9YXF-TNWC].

51. See Melanie Warner, Pandora’s Lunchbox: How Processed Food Took Over the 
The 1938 FDCA was ill-suited to ensuring safety with respect to these new kinds of foods. The adulteration provisions of 21 U.S.C. $\S 342$ distinguish between "added" and non-"added" poisonous or deleterious substances in food and impose differing standards for proving adulteration of each. ${ }^{52}$ In the case of "added" substances, the food is adulterated if the added substance "may render it injurious to health." ${ }^{53}$ If the deleterious substance is not "added," however, the food containing it is adulterated only if "the quantity of such substance in such food . . . ordinarily render[s] it injurious to health." ${ }^{54}$ Congress's intent was to impose stricter liability upon food producers for adulteration of food "by acts of man" rather than of nature, ${ }^{55}$ presumably on the ground that producers could control the former but not the latter. But in either case, the FDA bore the burden of proving adulteration. ${ }^{56}$ There was no pre-market approval requirement for substances added to foods.

By about 1950, Congress was aware of the changes food science had introduced and it began to worry about cancer and heart disease, both of which it believed could be caused by environmental contaminants and chemicals added to foods ${ }^{57}$ According to its title, the Food Additives Amendment of 1958 was enacted specifically " $\mathrm{t}$ ] o protect the public health by amending the Federal Food, Drug, and Cosmetic Act to prohibit the use in food of additives which have not been adequately tested to establish their safety." 58 Under the Food Additives Amendment of 1958, Congress provided a strict regime for oversight of food "additives." ${ }^{59}$ In short, such substances are to be presumed unsafe. ${ }^{60}$ Food

AMERICAN MEAL xiv (Scribner 2013) (noting that "[o]ver the last century . . . complex modes of production have ushered in a new type of eating, what we call processed food" and that the shift to a highly processed food supply "represents the most dramatic nutritional shift in human history"); see also H.R. REP. No. 2356, at 520-21 (1952) (noting that progress in food science in the "comparatively recent past" has led to introduction of chemical substances into food supply "at an ever-increasing rate").

52. See 21 U.S.C. $\S 342$ (a) (2012).

53. Id.

54. Id.

55. See United States v. Anderson Seafoods, Inc., 622 F.2d 157, 161 (5th Cir. 1980) (holding that the stricter "may injure" standard applies whenever "any of [the toxic] substance is shown to have been introduced by man").

56. 21 U.S.C. $\S 342$.

57. A 1952 House Report indicated that approximately 842 chemicals were thought to be in use in food at that time; of these, only about half were considered to be safe. H.R. REP. No. 2356, at 521 (1952). By December 1958, FDA had published an initial list of about 180 substances the agency considered to merit GRAS status. Frederick H. Degnan, Rethinking the Applicability and Usefulness of the GRAS Concept, 46 Food Drug CoSM. L.J. 553, 562 (1991).

58. See Food Additives Amendment of 1958, Pub. L. No. 85-929, 72 Stat. 1784 (codified as amended in scattered sections of 21 U.S.C.).

59. Id.

60. 21 U.S.C. $§ 348$. 
containing such additives is adulterated ${ }^{61}$ and its sale unlawful unless and until the producer establishes safety to the satisfaction of the FDA. The FDA's approval is reflected in the issuance of a food additive regulation "prescribing the conditions under which such additive may be safely used." ${ }^{2}$

Thus, recognizing that new additives coming into the market had little in common with traditional foods, Congress created a regulatory regime for "additives" that is the polar opposite, in terms of cost, delay, burden of proof, and other issues, of that for "food."

"Food additives" were broadly defined in the 1958 Act to include "any substance the intended use of which results or may reasonably be expected to result, directly or indirectly, in its becoming a component or otherwise affecting the characteristics of any food." ${ }^{3}$ "This definition includes the "chemical" substances commonly thought of as "additives": the innovations of food science, created in laboratories rather than occurring in nature, and having unfamiliar, industrial-sounding names. For these substances Congress mandated a pre-market approval regime whose hallmark was formal rulemaking based on rigorous scientific testing to establish safety. ${ }^{64}$

But Congress had no desire to thwart innovation in the food industry. ${ }^{65}$ The 1958 Act's definition of "food additives" literally includes common ingredients used in the preparation of traditional foods, like the flour, sugar, and eggs baked into a cake. These ingredients, despite meeting the definition of "additives," had long been accepted as safe for use in food. It was important to Congress that this kind of "additive" not be subjected to the new regime. ${ }^{66}$ In addition, some artificial additives could likely be shown by scientific testing to be safe. ${ }^{67}$ Congress therefore created an exception within the definition of "additives." 68 Substances meeting the broad definition of "additives" would be exempt from treatment as such if they were "generally recognized as safe" (GRAS) ${ }^{69}$ In this context, safety refers to the health of man or animal. ${ }^{70}$ As interpreted by the FDA, "general recognition" of safety means that the substance is generally recognized, among experts qualified by scientific training or experience to evaluate its safety to be safe for use in food. ${ }^{71}$ The seemingly limited GRAS exception is at the heart

61. Id. $\S 342(\mathrm{a})(2)(\mathrm{C})(\mathrm{i})$.

62. Id. $\S 348(\mathrm{a})(2)$.

63. See Food Additives Amendment $\S 201 ; 21$ U.S.C. 321(s).

64. See id. Food Additives Amendment $\S 409$.

65. See S. REP. No. 85-2422, at 5301 (1958) (discussing "unnecessary proscription" of the use of technological advances in food production as a "flaw in existing law").

66. See Food Additives Amendment $\S 201 ; 21$ U.S.C. 321(s).

67. Food Additives Amendment $\S 201$

68. Id.

69. 21 U.S.C. $\S 321(\mathrm{~s})$.

70. Id. $\S 321(\mathrm{u})$.

71. 21 C.F.R. $\$ 170.30$ (2015). FDA regulations made clear that not only the quality of the science, but also its acceptance after dissemination through scientific channels were important. Id. The standard was not unanimous acceptance, but a general consensus of scientific opinion as to 
of the failure of the regulation of food additives.

The seemingly limited GRAS exception, broadly interpreted by the FDA and the food industry, has swallowed the rule that food additives are presumed unsafe. $^{72}$ The effect of the GRAS exception is to treat the substance in question not as an "additive" warranting strict review, but as food itself. ${ }^{73}$ The Pew Charitable Trusts reported that in recent years almost all new chemical additives have gone into the food supply on GRAS self-determinations rather than by the formal FDA food additive approval process. ${ }^{74}$ Thus, additives, like traditional whole foods, are sanctionable only after reaching the market and causing harm. There is hardly a vestige of a pre-market approval regime. Given the FDA's legendary delays in responding to petitions for review of particular substances, ${ }^{75}$ additives may remain on the market for a long time and cause considerable harm in the interim. ${ }^{76}$

\section{A. The Demise of the Food Additive Regulation and GRAS Affirmation Processes}

Owing in large part to the vast and ever-increasing number of additives, the variety of purposes they serve and the number of products in which they appear, the rigorous oversight Congress had in mind has proven unworkable. In a series of steps over the ensuing decades, the oversight of additives has steadily broken down.

The years immediately following passage of the 1958 Act saw a flurry of activity by the FDA to review and approve substances then in use but not

safety. Id. § 170.3(i); see also Substances Generally Recognized as Safe, 62 Fed. Reg. 18,938-01 (proposed Apr. 17, 1997) (to be codified at 21 C.F.R. pt. 170).

72. Pew Charitable TrS., supra note 24 , at 1.

73. HutT \& MERRILL, supra note 23, at 397 (stating that the GRAS exception "expressly excludes a substantial portion, probably the majority," of substances otherwise defined as food additives). There is some confusion about whether GRAS status is an exception to the definition of or an exemption from treatment as a "food additive." See, e.g., Noah \& Merrill, supra note 48, at $441 \mathrm{n} .492$ (describing GRAS as a "definitional exception (or exclusion)," but noting that FDA has recently referred to GRAS as an "exemption").

74. Pew Charitable Trs., supra note 24 , at 1.

75. See ForTin, supra note 9, at 266, 268 (reporting that " $[\mathrm{t}]$ he new food additive approval process can take years to complete ... [and] the GRAS affirmation process for high fructose corn syrup took nine years).

76. For example, nearly twenty thousand adverse effect reports were made to the FDA on Olestra. See Petition from Michael F. Jacobson, Exec. Dir., Ctr. for Sci. in the Pub. Interest, to Lester Crawford, Deputy Comm'r, Food \& Drug Admin. (Apr. 16, 2002), available at https://www.cspinet.org/new/ltr_041602.html [http://perma.cc/8RY9-GMWA] (urging the FDA to "reject Procter and Gamble's and Frito-Lay's requests to delete the olestra label notice on packages of olestra-containing products [and instead] to require a prominent warning label on the fronts of packages stating that olestra can cause severe diarrhea or cramps.") (emphasis in original). 
GRAS. ${ }^{77}$ Among other things, the FDA endeavored to compile a list of GRAS substances as of 1958 while also reviewing new additive petitions. ${ }^{78}$ But that activity ground to a halt around 1970; in the succeeding three decades, the FDA approved only eight new direct food additives. ${ }^{79}$ Additive petitions "languished in the FDA pipeline" for years. ${ }^{80}$

Obtaining a food additive regulation is an onerous process. Such regulations require full notice and comment rulemaking. ${ }^{81}$ The producer must file a petition for approval of the use of the additive. ${ }^{82}$ Such petitions must contain a great deal of supporting information about the identity and composition of the additive, the proposed conditions of use, the intended effects of use and the quantity required to achieve those effects, and "full reports of investigations made with respect to the safety for use of such additive, including full information as to the methods and controls used in conducting such investigations." ${ }^{83}$ The regulation must prescribe the "conditions under which [the] additive may be safely used." 84 The Secretary is prohibited from issuing a regulation when:

[A] fair evaluation of the data ... fails to establish that the proposed use ... under the conditions of use to be specified in the regulation, will be safe: Provided, that no additive shall be deemed to be safe if it is found to induce cancer when ingested by man or animal ... [or] shows that the proposed use of the additive would promote deception of the consumer . $\ldots$ or would otherwise result in adulteration or misbranding of food $\ldots{ }^{85}$

These complexities at least partly explain the burden on additive proponents and the slow response by the FDA.

While food additive petitions languished, the FDA published proposed regulations outlining a new "GRAS affirmation" procedure in $1974 .{ }^{86}$ Under this approach producers would self-determine the safety of a substance under the scientific criteria of the 1958 Act rather than petitioning FDA for a regulation. ${ }^{87}$ Producers were permitted to market their products immediately following selfdetermination of safety. ${ }^{88}$ They could also, if they desired to bolster acceptance

77. HutT \& MERRILL, supra note 23, at 424.

78. Id.

79. Id. at $424-25$.

80. Id. at 425 .

81. 21 U.S.C. $§ 348$ (2012).

82. Id.

83. Id.

84. Id.

85. Id.

86. General Recognition of Safety and Prior Sanction for Food Ingredients, 39 Fed. Reg. 34,194-01 (proposed Sept. 23, 1974) (to be codified at 21 C.F.R. pt. 121). This proposed rule, as revised, was adopted in 1976 and took effect in 1977. See generally 21 C.F.R. $§ 170$ (2015).

87. General Recognition of Safety and Prior Sanction for Food Ingredients, 39 Fed. Reg. 34,194-01.

88. Id. 
of the substance in the market, seek the FDA's "affirmation" of their GRAS selfdeterminations ${ }^{89}$ Producers filed many such petitions and a huge backlog quickly developed. ${ }^{90}$

\section{B. The Rise of GRAS Status}

Securing GRAS status is easier than obtaining a food additive regulation. The 1958 Act provides two paths to establishing GRAS status. ${ }^{91}$ The first applies to traditional ingredients, like sugar and salt. Such ingredients could achieve GRAS status by being "adequately shown through . . . experience based on common use in food" prior to 1958 "to be safe under the conditions of . . . intended use." "common use" exemption because they are either new or used in new ways. For these substances, GRAS status could be achieved only by being "adequately shown through scientific procedures . . . to be safe under the conditions of . . . intended use." ${ }^{93}$ FDA regulations elaborate on the nature of the scientific evidence required, specifically providing that the quantity and quality of proof for achieving GRAS status through the scientific evidence route is to be the same as that required to obtain a regulation permitting use of the additive under specified conditions. ${ }^{94}$ Achieving "general recognition" of safety via the scientific evidence route ostensibly requires publication in the scientific literature. ${ }^{95}$ Establishing GRAS status by this route thus eliminated the need to go through notice and comment rulemaking, but otherwise was not intended to

89. Id.

90. Food Additives 210 (A. Larry Branen et al. eds., 2d ed. 2002).

91. Food Additives Amendment of 1958, Pub. L. No. 85-929, 72 Stat. 1784 (codified as amended in scattered sections of 21 U.S.C.). There is also an exemption for substances already sanctioned by formal action of the FDA or the USDA. Id. This closed set functions differently from GRAS status and is not discussed in this Article.

92. 21 U.S.C. $\$ 321(\mathrm{~s})$ (2012). The set of articles with a history of common use in food prior to 1958 is also closed. Even if this provision allows other articles to achieve GRAS status based on a history of common use after 1958, those new ingredients would be few under the definitions of traditional food ingredients and food additives proposed herein. See infra Part II.

93. General Recognition of Safety and Prior Sanction for Food Ingredients, 39 Fed. Reg. 34,194-01 (proposed Sept. 23, 1974) (to be codified at 21 C.F.R. pt. 121) (interpreting the 1958 Act).

94. 21 C.F.R. $\S 170.30$ (b) (2015). These standards were originally adopted in 1977. See Reorganization and Republication, 42 Fed. Reg. 14483 (Mar. 15, 1977) (codified at scattered sections of 21 C.F.R.). The 1980 GAO Report, however, cited a study stating that "[o]nly a small fraction of . . GRAS substances . . . are supported by an array of tests that compare with those required for the approval of new food additives." Gen. Accounting OfFice, NEED for More Effective Regulation of Direct Additives of Food 12 (1980) (quoting Federation of Am. Socs. for Experimental Biology, Evaluation of Health Aspects of GRAS Food INGREDIENTS: LESSONS LEARNED AND QUESTIONS UNANSWERED 31 (1977)).

95. 21 C.F.R. $\S 170.30($ b). 
water down the required demonstration of safety. A 1973 Supreme Court decision reinforces this understanding. ${ }^{96}$

The 1974 GRAS "affirmation" procedure, described above, ${ }^{97}$ began the shift from agency evaluation to producer self-determination but explicitly preserved the 1958 Act's scientific standards and required producers to submit full, not summary, data. ${ }^{98}$ In 1997, FDA published proposed rules for a new voluntary "GRAS notification" process. ${ }^{99}$ Under this procedure, a producer can make its own determination of safety, send its product to market, and, if it wishes to do so, notify the FDA that it has determined that its product is GRAS for the intended use. ${ }^{100}$ Producers under this scheme submit only a summary of the scientific data on which they rely. ${ }^{101}$ The FDA makes no independent review of safety or even of the data proffered to establish safety. ${ }^{102}$ The FDA responds only that it either does or does not have any objection to the notification. ${ }^{103}$ Producers have found this procedure, lacking any FDA imprimatur of GRAS status, of little use. Notifications have fallen, with the result that the FDA has less information than ever before about the additives present in the food supply. ${ }^{104}$

\section{The Consequences of the Distinction}

For food producers, establishing GRAS status makes all the difference in the regulatory treatment-and hence, marketability - of a substance. With it, as noted above, a producer may send products containing additives to market free of any pre-market approval requirement. ${ }^{105}$

Without GRAS status, the additive may not be used in products to be sold in interstate commerce unless "there is in effect, and it and its use or intended use are in conformity with, a regulation ... prescribing the conditions under which

96. See Weinberger v. Hynson, Westcott \& Dunning, Inc., 412 U.S. 609 (1973) (reviewing an FDA regulation establishing minimum criteria for general recognition of scientific evidence of efficacy of drugs).

97. See text accompanying notes 79-82.

98. See Degnan, supra note 57, at 570-71 (discussing changes in the FDA's approach to GRAS status of foods).

99. Substances Generally Recognized as Safe, 62 Fed. Reg. 18,938-01 (proposed Apr. 17, 1997) (to be codified at 21 C.F.R. pt. 170).

100. Id.

101. Id.

102. Id.

103. Id.

104. Tom Neltner \& Maricel Maffini, Nat'L Res. Def. Council, Generally ReCognized as Secret: Chemicals Added to Food in the United States (2014), available at http://www.nrdc.org/food/files/safety-loophole-for-chemicals-in-food-report.pdf [http://perma.cc/527E-EA3L] (noting that over 1000 chemicals have been determined by manufacturers to be safe since 1997).

105. 21 U.S.C. $§ 348$ (2012). 
such additive may be safely used." ${ }^{106}$ Any product containing the presumably unsafe additive would be "adulterated" under 21 U.S.C. § 342(a)(2)(C). As adulterated food, the product would be subject to enforcement actions including injunction $^{107}$ and seizure. ${ }^{108}$ A leading scholar characterized the difference as "[taking] the GRAS superhighway to market" as opposed to "follow[ing] the meandering food additive path through the FDA woods." 109 Accordingly, "there is only one type of food substance worth [a producer's] consider[ation]: a GRAS substance that can immediately be marketed." 110

For consumers, much of the protection Congress intended has vanished. Not only does the FDA today not review most additives prior to their appearance in the marketplace, the FDA lacks even a comprehensive list of all additives currently in use. Producers of food additives, or of the foods in which they appear, may - but are not required to - notify the FDA of their use. The FDA conducts no real review and issues no ruling with respect to additives of which it is notified; producers are free to use and market them based on nothing more than their own determination of their safety. Such determinations often are conducted by the producer's own experts working under a conflict of interest ${ }^{111}$ and do not adhere to the standards of scientific rigor called for in the 1958 Act. ${ }^{112}$

\section{Summary}

Though final regulations establishing the 1997 proposed notification procedure were never issued, the FDA has used this procedure to the exclusion

106. Id. $\S 348(\mathrm{a})(2)$.

107. $I d . \S 332$.

108. Id. $\S 334$.

109. Food AdDitives, supra note 90, at 208.

110. Id. at 205 .

111. Noah \& Merrill, supra note 48, at 359-64 (discussing “private GRAS determinations"); see also GEN. ACCOUNTING OFFICE, supra note 2, at 14-16 (discussing conflicts of interests among experts hired by companies to make GRAS determinations regarding the companies' products).

112. Producers do remain responsible after the fact for the deleterious effects of GRAS substances and are subject to the general enforcement mechanisms of the FDCA. See generally 21 U.S.C. $\S \S 301-399$ f. Those mechanisms include injunction against further sale, criminal and civil penalties, seizure of goods, and debarment. See id. \$§ 331-337a. All such mechanisms are initiated by the FDA and only after the food has reached the market and caused harm to consumers. See id. $\S 337$. If the FDA disagrees with a producer's determination that a substance is GRAS (an event extremely unlikely to occur under the 1997 voluntary notification procedure) and if the producer continues to market products containing the additive, the FDA may initiate an enforcement action. See HutT \& MERRILL, supra note 23, at 1273. In that action, however, the FDA would bear the burden of proving that the substance is not GRAS. Id. (stating that in enforcement actions, the FDA "must prove its case by a preponderance of the evidence"). By contrast, additive proponents bear the burden of "establish[ing] that the proposed use of the food additive ... will be safe". 21 U.S.C. $\S 348(\mathrm{c})(3)(\mathrm{A})$. 
of the former affirmation process for nearly two decades. ${ }^{113}$ Thus, as others have documented, ${ }^{114}$ the FDA is operating under a procedure not authorized by statute, not set forth in any regulation with the force of law, and not open to public scrutiny. Under the 2014 consent decree mentioned above, the FDA is obligated to finalize the regulations by August $2016 .{ }^{115}$ Lacking any order to reinvigorate the GRAS review process, the consent decree seems too little, too late. This Article argues for additional, substantive changes to restore rigor in the regulation of food additives.

\section{Definitions}

The definitions of food and food additives are important but problematic. ${ }^{116}$ Regulatory authority and treatment depend entirely on the classification of a comestible substance as "food" or "additive." But the definitions are partially overlapping, depend on additional, undefined terms, and are complicated by the confusing GRAS exception. Before attempting to reinvigorate the regulation of additives, it makes sense to address the definitional problems.

\section{A. Overlapping Definitions of Food and Food Additives}

The FDCA governs the sale in interstate commerce of "food." 117 The FDA's enforcement authority with respect to the food supply hinges on statutory definitions. ${ }^{118}$ The 1938 Act defines "food" to "mean[] (1) articles used for food or drink for man or other animals ... [and] articles used for components of any such article." "119 The terms "article" and "component" are not defined. Congress probably defined "food" so broadly in order to authorize the FDA to ensure the safety of all food ingested by humans. The definition is functional, not based on the origin of the food. Hence, an item is a "food" if it is used "in the ordinary

113. See generally How U.S. FDA's GRAS Notification Program Works, Food \& DRUG ADMIN., http://www.fda.gov/Food/IngredientsPackagingLabeling/GRAS/ucm083022.htm [http://perma.cc/X8ZY-9XKG] (last updated Apr. 1, 2015).

114. Ctr. for Food Safety Complaint, supra note 25, at 22-23.

115. Consent Decree, supra note 44.

116. See Noah \& Merrill, supra note 48, at 341 (noting that interpretation of the "definition of the term 'food additive' has posed significant difficulties").

117. Id. Though included within the definition of "food," meat and a few other articles are assigned for regulatory purposes to USDA. See, e.g., 21 U.S.C. §§ 451-472 (2012) (addressing poultry and poultry products inspection).

118. See Hutt \& Merrill, supra note 23, at 28 (noting that the 1938 Act "gave FDA authority over four broad categories of products," including food, and that the "statutory definitions of these categories ... delineate the outer boundaries of the arena within which the agency operates ... and control[] the shape pf the regulatory regime the agency will impose").

119. 21 U.S.C. § 321(f). The definition was largely unchanged in substance from that of the 1906 Pure Food Act, which provided that the term "food" "shall include all articles used for food, drink, confectionery, or condiment by man or other animals, whether simple, mixed, or compound." Federal Food and Drugs Act of 1906, 34 Stat. $738 \S 6$ (1906) (repealed in 1938). 
way most people use food-for its taste, aroma, or nutritive value." 120 "Food" includes not only traditional whole foods but also prepared foods, processed food products and articles of artificial origin if used as such. "Food" also includes live animals intended for use as food after slaughter, ${ }^{121}$ as well as feed ingested by animals, presumably because animal feed may affect the meat or dairy products later consumed by humans. ${ }^{122}$ The definition of food even encompasses items rejected as food ${ }^{123}$ or unfit for consumption, ${ }^{124}$ as well as food packaging materials. ${ }^{125}$

By virtue of including "components" of food, the definition of "food" extends to all ingredients of food and anything else that is added to or migrates into food. Congress thus ensured that the FDA has authority to regulate components of food that are not themselves "food." Under the 1938 Act, "components" of food were regulated in the same way as whole foods - they were presumed safe and were subject only to post-market sanctions. ${ }^{126}$ Hence, under the 1938 Act, "the federal government [was] unable to prevent the use in foods of a poisonous or deleterious substance until it first prove[d] that the additive [was unsafe for use in food]," generally through animal experimentation taking two years or more. ${ }^{127}$ Congress undertook to remedy this "huge loophole" 128 in then-existing law by passing a bill "to prohibit the use in food of additives which have not been adequately tested to establish their safety." 29

Under the 1958 Food Additives Amendment, by contrast, "food additives"

120. Nutrilab, Inc. v. Schweiker, 713 F.2d 335, 338 (7th Cir. 1983). "Taste" may be understood broadly to mean within a range of flavors generally acceptable to humans, not exceedingly bitter or putrid, which may indicate the food is dangerous to consume and not to refer to individual or cultural preferences which may differ or change over time. "Nutritive value" may be understood to mean that the article of food provides calories at least and maybe other nutrients, whether or not in keeping with current nutritional guidelines.

121. United States v. Tuente Livestock, 888 F. Supp. 1416, 1424 (S.D. Ohio 1995).

122. See generally S. REP. 85-2422 (1958) (discussing impact of poultry feed on eggs and of cattle feed on milk or edible flesh of the animal).

123. United States v. Tech. Egg Prods., Inc., 171 F. Supp. 326, 327 (N.D. Ga. 1959) (holding that so long as an item retains a semblance of the identity it possessed as food, it remains a food under the Act).

124. 21 U.S.C. $§ 342$ (2012) (noting a food may be adulterated if it is "unfit for food").

125. Natick Paperboard Corp. v. Weinberger, 525 F.2d 1103, 1104 (1st Cir. 1975) (stating that PCBs in paper food packaging materials may migrate into food and thus come within the definition of "food" as components of food); United States v. Articles of Food, 370 F. Supp. 371, 373 (E.D. Mich. 1974) (stating that lead in pottery used to prepare or serve food, if it migrates into food, is "food" under the FDCA).

126. Food Drug and Cosmetic Act of 1938, Pub. L. No. 75-717, 52 Stat. 1040.

127. S. REP. No. 85-2422; see also Degnan, supra note 57, at 554-56 (describing problems under the 1938 Act and Congress's approach to remedying them in the 1958 Act); Noah \& Merrill, supra note 48 , at 332-40 (same).

128. S. REP. No. 85-2422.

129. Id. 
are presumed unsafe and are subject to pre-market approval. ${ }^{130}$ The definition of "additives" is broad but also subject to an important exception. ${ }^{131}$ The definition itself reads:

The term "food additive" means any substance the intended use of which results or may reasonably be expected to result, directly or indirectly, in its becoming a component or otherwise affecting the characteristics of any food (including any substance intended for use in producing, manufacturing, packing, processing, preparing, treating, packaging, transporting, or holding food; and including any source of radiation intended for any such use) . . . . ${ }^{132}$

As in the definition of food, Congress aimed for inclusivity so as to assure the safety of the many new substances and processes used to produce the processed and packaged foods that were flowing into the market. ${ }^{133}$

But the definition of "additive" incorporates a proviso worded in the negative: "if such substance is not generally recognized . . . as having been adequately shown ... to be safe under the conditions of its intended use." ${ }^{134}$ To put the matter affirmatively, substances meeting the definition of "additive" are immediately excluded from that category if they are GRAS. ${ }^{135}$ In practical effect,

130. Food Additives Amendment of 1958, Pub. L. No. 85-929, 72 Stat. 1784 (codified as amended in scattered sections of 21 U.S.C.).

131. Id.

132. 21 U.S.C. § 321(s) (2012). The FDA's definition of "food additives" elaborates on what is meant by "affecting the characteristics of food." 21 C.F.R. $§ 170.3(e)(1)(2015)$. Substances used to give a food or food ingredient a "different flavor [or] texture," for example, do affect the characteristics of the food and are additives. Id. Materials that achieve purely "physical effects, [such] as protecting the contents of packages, preserving shape, and preventing moisture loss"-provided that they do not migrate into the food - neither become components of nor affect the characteristics of the food and therefore are not additives. Id.

133. S. REP. No. 85-2422, at 5301 (speaking generally of desire to address "the use of such additives as our technological scientists may produce").

134. 21 U.S.C. $\S 321(\mathrm{~s})$.

135. The definition of additives also excludes pesticides, pesticide chemical residues, color additives, and prior-sanctioned substances. $I d$. Pesticides are regulated by a separate statute (the Federal Insecticide, Fungicide, and Rodenticide Act). See 7 U.S.C. $\S 136-136 y$ (2012). Pesticide chemical residues and color additives are treated elsewhere in the FDCA. See 21 U.S.C. $\S \S 346 a$, 379 e (2012). Prior-sanctioned substances are permanently exempt from regulation as food additives under the 1958 Act by virtue of prior determinations by the FDA or the USDA. See HutT \& MERRILL, supra note 23, at 419 (noting that prior-sanctioned substances are not regulated as additives and are not subject to contemporary evaluations of safety, but may be regulated under the provisions relating to adulteration of "food," including "components of food"); id. at $414 \mathrm{n} .5$ (describing the permanence of the exemption). Because all these substances either have already been reviewed and found safe, or are regulated elsewhere, it makes sense to exclude them from regulation under the food additive regime. They are unlike GRAS substances and are not discussed in this Article. 
GRAS substances are regulated not as "additives" but as "food." This exclusion drastically reduces the category of food additives subject to strict review.

\section{B. Lack of Clarity Regarding “Components” of Food}

As noted above, the FDCA's definition of "food" includes "components" of food. ${ }^{136}$ The statutory term "component" extends literally to both traditional, naturally occurring food ingredients and chemical or synthetic substances. ${ }^{137}$ Food additives usually remain in the finished food and thus meet the statutory definition of "food." In order to make clear that additives receive different regulatory treatment than food itself, Congress defined a new category-food additives - in 1958. " ${ }^{138}$ "Additive" includes "substances" intentionally added to food that become "components" of the food. ${ }^{139}$ The FDA has interpreted "substance" in the definition of "food additive" as "includ[ing] a food or food component consisting of one or more ingredients." ${ }^{140}$ It thus appears that some substances that become components of food-traditional food ingredients such

136. 21 U.S.C. $\S 321(\mathrm{f})$.

137. Interpretation of the term "components" broadly to encompass additives is necessary in order for the FDA's regulatory authority to encompass substances that get into human food indirectly, including substances fed or administered to animals that become human food and substances that migrate into human food from food packaging materials. Judicial gloss on the term "component" suggests:

For the component element of the definition to be satisfied, Congress must have intended the Commissioner to determine with a fair degree of confidence that a substance migrates into food in more than insignificant amounts. We do not suggest that the substance must be toxicologically significant . . . Nor is it necessary that the level of migration be significant with reference to the threshold of direct detectability ... Although as a matter of theory the statutory net might sweep within the term food additive a single molecule of any substance that finds its way into food, the Commissioner . . . may determine based on the evidence before him that the level of migration into food of a particular chemical is so negligible as to present no public health or safety concerns, even to assure a wide margin of safety.

Monsanto Co. v. Kennedy, 613 F.2d 947, 950 (D.C. Cir. 1979) (internal quotation marks omitted) (discussing chemicals used intentionally in food packaging and migrating from there into food).

138. 21 U.S.C. $\S 321$ (s).

139. Only some additives are "components," however. "Additives" extends also to substances that "otherwise affect[] the characteristics of any food ...." Id. (emphasis added). For a discussion of the confusing uses of the terms "component" and "additive," see also United States v. 29 Cartons of an Article of Food, 987 F.2d 33, 34 (1st Cir. 1993) and United States v. Two Plastic Drums, 984 F.2d 814, 815-16 (7th Cir. 1993). Both cases involved capsules containing black currant oil and both rejected interpretation that all components of food are "additives." 29 Cartons of an Article of Food, 987 F.2d 33; Two Plastic Drums, 984 F.2d 814.

140. 21 C.F.R. $\S 170.3$ (g) (2015). This provision makes clear that "additives" and "food" are overlapping categories under the statute as currently written. Id. 
as sugar or salt - literally meet the definition of both "additives" and "food." "141 This overlap is confusing given that "food" and "additives" are regulated very differently.

It is unclear whether or how "components" differ from "ingredients." The FDCA does not define "ingredients;" the statute's usage of the term is ambiguous. 21 U.S.C. $§ 343$, for example, requires a list of "ingredients" on the label by "common name" when a food is "fabricated of two or more ingredients." 142 It appears from a perusal of current labels that the "ingredient" listing mandate applies to additives. The listing of all additives - whether or not they become components of food - is desirable to ensure safety and to lessen consumer confusion or deception. ${ }^{143}$ But most additives do not have "common names," so it is unclear that they are "ingredients" required to be listed on the label. On the other hand, use of the term "fabrication" in the ingredient listing mandate suggests an industrial process, the type of food production that often involves the use of additives.

FDA publications sometimes use the term "ingredients." 144 For example, the FDA stated in a 1973 Notice that "each food ingredient will be proposed for inclusion in one of [several regulatory categories]," such as direct human food additives, prior sanctioned substances, indirect human food additives, and interim human food additives. ${ }^{145}$ Consistent with the statute's use of the term "ingredients," the FDA's usage here would appear to include both traditional food ingredients used by the home cook and chemical or synthetic additives used by food producers. It would be clearer to delineate two separate categories - ingredients and additives - receiving different regulatory treatment.

141. Cf. Noah \& Merrill, supra note 48, at 342-43 (noting that although Congress focused on chemical additives, "items commonly available as food may be food additives" too).

142. 21 U.S.C. $\S 343$.

143. Some substances used intentionally to achieve a functional effect in food during the course of processing are exempt from the requirement to be listed in the label because they are thought not to remain in the food. See Inspection Serv., Food \& Drug Admin., Compliance Guide on the Determination of Processing Aids (Apr. 8, 2008), available at http://www.fsis.usda.gov/wps/wcm/connect/9a34e8d9-997a-4c58-bd5e-d87cc371 ecda/ Determination_of_Processing_Aids.pdf?MOD=AJPERES [http://perma.cc/Q9DX-672S]. For that reason, these substances are classified as "processing aids," not as components of food. Id. Examples include gases in a process called Modified Atmosphere Packaging (used to preserve appearance of meat and other foods) and the ammonia used to kill pathogens in a ground beef product known as Lean Finely Textured Beef. See, e.g., FDA Food Code 2009, Annex 6 - Food Processing Criteria, Food \& DRUG ADMIN., http://www.fda.gov/Food/FoodSafety/Retail FoodProtection/FoodCode/FoodCode2009/ucm188201.htm [http://perma.cc/ZY58-X6Y5] (last updated Dec. 23, 2014); Michael Moss, Safety of Beef Processing Method Questioned, N.Y. TimEs, Dec. 31, 2009, at A1, available at http:/www.nytimes.com/2009/12/31/us/31meat.html [http:// perma.cc/KC8C-XRRN].

144. See, e.g., Status of Review of GRAS and Prior Sanctioned Direct Human Food Ingredients, 38 Fed. Reg. 20,054-02 (July 27, 1973).

145. Id. at 20,055 (emphasis added). 


\section{Distinguishing Traditional "Ingredients" from Novel "Additives"}

The functional gloss on the statutory definition of "food"-articles used for taste, aroma, or nutritive value-clearly encompasses traditional food ingredients. But the overlapping definitions of "food" and "food additives" create an anomaly. Because articles of traditional food, such as sugar, salt, eggs, butter, milk, and a host of others are added to foods intentionally to affect characteristics such as flavor or texture, the current definition of "additives" also encompasses these items. ${ }^{146}$ A pre-market approval scheme is obviously inappropriate for traditional food ingredients. ${ }^{147}$ To achieve this result, the statute treats traditional food ingredients initially as "additives" and then immediately excludes them as GRAS on the basis of their familiarity as traditional foods or components of food. Although syntactically convoluted, section 321 tracks Congress's bottom line distinction: traditional foods are presumed safe to market because their safety can be evaluated by ordinary consumers using their senses and experience. ${ }^{148}$ Chemical additives, on the other hand, are presumed unsafe and must be proven otherwise before entry into the market precisely because ordinary consumers cannot detect such additives or evaluate their safety for themselves. ${ }^{149}$

It would be simpler to achieve that result by removing traditional food ingredients from the definition of "additives" altogether. This could be accomplished by defining the term "ingredient" to mean traditional foods used in home kitchens as ingredients in other foods, while reserving the term "additives" for non-naturally occurring substances added to food by producers or processors. ${ }^{150}$ To reestablish the distinction Congress had in mind between

146. Cf. Noah \& Merrill, supra note 48, at 342-43 (noting that although Congress focused on chemical additives, "items commonly available as food may be food additives" too).

147. Cf. id. at 350-51 (discussing the legislative history of the GRAS provision and noting that the exception "attempts to minimize the burden that otherwise would have fallen on both the food industry and the government if the FDA had to evaluate and affirmatively approve all common substances used in food").

148. This presumption of safety does not always hold true and it can be rebutted. Recently, a variety of traditional ingredients have come under attack as unsafe, at least for some people, at excessive levels of consumption. Both Michael Moss and Dr. David Kessler, for example, discuss the dangers presented by sugar, fat, and salt. Moss, supra note 1, at xvii-xix (discussing health effects); $i d$. at xxv (discussing "methodical engineering" of foods to hit the "bliss point" of sugar, salt, or fat "guaranteed to create a craving"); DAvid A. KeSSLER, The END OF OverEATING 12-17 (Rodale Books 2010) (discussing tendencies to overeat foods high in sugar, fat, or salt). Dr. Robert Lustig takes aim at sugar in particular. RoBert Lustig, FAT CHANCE 19-21 (Penguin Grp. 2013) (linking the obesity epidemic to increased consumption of sugars). Laurie Beyranevand suggests that sugar should be treated as an additive, not as GRAS despite its status as a traditional food. Laurie Beyranevand, Generally Recognized as Safe?: Analyzing Flaws in the FDA 's Approach to Additives, 37 VT. L. REV. 887, 920 (2013).

149. Beyranevand, supra note 148 , at 888 .

150. The devil in statute-drafting is always in the details, but one way to begin thinking about 
traditional food ingredients and new chemical additives, "ingredients" and "additives" must be understood as mutually exclusive categories.

1. Ingredients. - It seems appropriate to define the term "ingredients" as the home cook understands it: traditional food items of the sort listed in a recipe. ${ }^{151}$ Doing so does not change the statute's end result: traditional food ingredients are currently regulated (by virtue of the GRAS exception) as food, not as additives. ${ }^{152}$ The proposed approach would achieve the same result by a more streamlined process. Traditional ingredients would simply be classified as food, whether they may be consumed as food in their own right, like eggs, or only as part of a prepared food, like flour. As "food," traditional ingredients would be presumed safe under the statute and exempt from any pre-market approval requirement without need to resort to the GRAS exception. To preserve stricter oversight of "additives," however, the term "ingredient" must be limited to its ordinary meaning: traditional, naturally occurring ingredients available to home cooks. ${ }^{153}$

2. Additives.-To draw a sharp line differentiating additives from traditional foods, the term "additives" must be defined as extending only to artificial or synthetic substances incorporated into industrially-produced, packaged foods. Examples of additives include emulsifiers like carrageenan and various gums, sweeteners like HFCS, and artificial flavors. Emulsifiers, for example, bind ingredients together and prevent them from separating in the package. ${ }^{154}$ Artificial sweeteners and flavorings substitute for traditional sweeteners and flavorings because the traditional ingredients are either more expensive or do not

the definition of "ingredients" would draw upon the admonition that an item is not a traditional food if your grandmother would not recognize it as such. Michael Pollan, In DEFENSE OF Food: An Eater's Manifesto 147-50 (Penguin Press 2008). The FDCA uses the term "ingredient," for example, in section 343(i), which requires ingredients be listed by their "common name," when a food is "fabricated of two or more ingredients." 21 U.S.C. 343(i) (2012). Another thought is that traditional foods and food ingredients occur in nature and are able to be consumed with no more than minimal processing such as chopping, cooking, canning, or freezing.

151. The dictionary definition of "ingredient" is "any of the things a mixture is made of" (using the example of ice cream). Ingredient, Webster's New Twentieth CENTURy Dictionary 942 (2d ed. 1966).

152. Beyranevand, supra note 148 , at 893 .

153. With respect to unrelated statutory language, the Supreme Court held it appropriate to interpret food-related terms in their common and ordinary sense. Nix v. Hedden, 149 U.S. 304 (1893) (holding tomatoes to be vegetables for purposes of a tariff statute because they are generally served with the "principal part of the repast, and not ... as dessert" despite botanical classification as a fruit).

154. Faye Flam, Study Suggests Chemical "Emulsifiers" in Food Are Disrupting Gut Microbes and Making us Fat, FoRBES (Feb. 26, 2015, 10:56 AM), http://www.forbes.com/sites/ fayeflam/2015/02/26/study-suggests-chemical-emulsifiers-in-food-are-disrupting-gut-microbes-andmaking-us-fat/ [http://perma.cc/PB49-5669] ("Emulsifiers are ubiquitous in food products because they help otherwise unmixable ingredients blend together - making salad dressings, ice cream and cream cheese smooth.”). 
hold up well over the expected shelf life of packaged food products. ${ }^{155}$ Without these additives to affect flavor, texture, and shelf life, consumers might hesitate to accept processed and packaged foods as food. Such substances are not generally used or available for use in the home kitchen. "Additives" should be understood for what they are: substances used in food products that are not themselves "food."

The definition of "additive" also includes substances used in a variety of production steps including producing, processing, packaging, and transporting food-notably, food contact substances such as the BPA used in a can liner to protect the food from off-flavors caused by a reaction between the food and the can itself. ${ }^{156}$ These "indirect" or "incidental" additives are intended neither to become a component of the food nor to affect the characteristics of the food in a traditional sense. ${ }^{157}$ But if the food contact substance "migrate[s], or may be expected to migrate, into food [at non-negligible levels]," it becomes a component of the food and is an "additive." "158

All these artificial or synthetic substances fit well within Congress's 1958 definition of "additives." The existing definition of "additives" also includes the process of irradiation. ${ }^{159}$ Radiation is, of course, not a "substance," and it does not easily fit into the notion that additives are "components" of food. ${ }^{160}$ It was in 1958 a new technology, largely unfamiliar to the public, and for that reason, among others, it was a source of concern to many. ${ }^{161}$ Its explicit inclusion within the definition of "additives" reinforces the point that Congress was aiming at

155. Cf. Noah \& Merrill, supra note 48 , at 330.

156. Id.

157. There is another category of substances used intentionally but not intended to become part of the food or to affect the characteristics of the food. An example would be a "processing aid" such as the ammonia added to beef trimmings to help extract meat from fat in producing lean, finely textured beef (also called "pink slime" mixed in with other ground beef). Jim Avila, 70 Percent of Ground Beef at Supermarkets Contains 'Pink Slime,' ABC News (Mar. 7, 2012), http://abcnews. go.com/blogs/headlines/2012/03/70-percent-of-ground-beef-at-supermarkets-contains-pink-slime/ [http://perma.cc/AWC3-3ADM]. Ammonia is not a food in its own right. Though it is used intentionally during processing to kill pathogens, the ammonia is not an "additive" because (in theory) it does not remain in the beef in significant amounts; thus, it does not become a "component" of the ground beef. Nor is it used to "affect the characteristics" of the ground beef in a functional way, such as to alter flavor or texture, though it may have discernible effects on flavor and texture. Under current law, the ammonia would not be subject to regulation as either a food or an additive. Whether this treatment of processing aids comports with the statute is a question beyond the scope of this Article.

158. Cf. 21 C.F.R. 170.3(e) (2015); see also Natick Paperboard Corp. v. Weinberger, 525 F.2d 1103, 1107 (1st Cir. 1975) (holding that PCBs found in paper food packaging materials can be regulated as food additives).

159. Cf. Noah \& Merrill, supra note 48, at 337-38.

160. For simplicity and conciseness, this Article includes radiation within the concept of substances without further elaboration.

161. FORTIN, supra note 9, at 307. 
substances - and processes - that were not available to home cooks or well understood by consumers. And it suggests that Congress intended to address broadly all substances and technologies not already known to be safe for use in food. ${ }^{162}$

3. Natural Versus Artificial Origin.-This Article proposes that "food," including traditional ingredients, be distinguished from additives on the basis of natural as opposed to artificial or synthetic origin. Traditional, naturallyoccurring food ingredients are not what worried Congress in 1958. A 1952 House Report states:

Chemical substances are being introduced into the production, processing, storage, packaging, and distribution of food at an ever increasing rate. There is hardly a food sold in the market place today which has not had some chemicals used on it or in it ...

$[T]$ here is a genuine need for the use of many chemicals in connection with our food supply. . . . The progress that has been made in food technology, however, has been attended by a certain degree of hazard, since some quantity of . . . the new chemicals utilized in the production of food is inevitably ingested by the consuming public. It is essential that this risk be kept to a minimum. ${ }^{163}$

After several years of further deliberation, a Senate committee reported that the 1958 bill, if enacted, "would put upon the producer rather than our government the burden of proving that a newly discovered substance which a processor of foodstuffs proposes to add to the food we eat is safe." ${ }^{\prime 64}$ It is these unfamiliar, artificial substances that Congress intended to regulate strictly to ensure safety. ${ }^{165}$ The Senate Committee "urg[ed] amending the [1938 Act] so that chemicals employed in or on foods would be subjected to substantially the same safety requirements as exist in the law for new drugs."166

The proposed definition of "ingredients" and "additives" as mutually exclusive categories distinguished on the basis of natural or artificial origin comports with everyday usage. The Government Accounting Office's ("GAO") 1993 report states simply: "Foods are whole foods - such as fruits, vegetables, and grains - and processed foods made from whole foods." ${ }^{167}$ The statutory

162. Whether the inclusion of this process within the definition of additives suggests that other new processes, such as genetic engineering or nano-technology, should also be considered to be food additives is a question beyond the scope of this Article. For a discussion of legislative and regulatory gaps with respect to new food technologies, see GEN. ACCOUNTING OfFICE, InNOvATIVE Strategies May be Needed to Regulate New Food Technologies (1993), available at http://www.gao.gov/assets/220/218451.pdf [http://perma.cc/CG7B-HH7N].

163. H.R. REP. No. 82-2356 (1952).

164. S. REP. No. 85-2422, at 5305 (1958).

165. $I d$.

166. Id.

167. Gen. Accounting Office, supra note 162 , at 3. 
reference to ingredient listing by "common name"168 suggests that ingredients were generally understood as traditional food items. The listing of ingredients is intended to inform ordinary consumers of what the product contains. Many food additives have only chemical names; even if they also have common names most people probably do not recognize those names as referring to additives. ${ }^{169}$ The use of a common name for an additive would thus increase consumer confusion about what the food contained and might promote deception about the value of the food. Consider a familiar example: sugar is a traditional food ingredient, ${ }^{170}$ recognized by ordinary consumers as safe based on common knowledge of its history of use in food. ${ }^{171}$ High fructose corn syrup ("HFCS") is not a traditional ingredient that consumers are able to evaluate. ${ }^{172}$ Because consumers are unfamiliar with this substance and cannot evaluate its safety, it is to be treated as an additive. Listing HFCS as sugar would be misleading even if it is true that it is processed identically in the body. ${ }^{173}$

168. 21 U.S.C. § 343(i) (2012).

169. For example, many people assume that "citric acid" refers to the product of a citrus fruit, when in fact it is often manufactured from corn. See, e.g., Michael Pollan, The Omnivore's DilEMMA 18-19 (Penguin Grp. 2007) (describing the presence of corn in citric acid and numerous other food additives); Y.D. Hang \& E.E. Woodams, Production of Citric Acid from Corncobs by Aspergillus Niger, 65 BioResourCE TeCH. 251-53 (1998).

170. This is so regardless whether the sugar was derived from sugar cane or sugar beets. The substance that results is the same-sucrose-despite differences in source plant or details of production. Miriam Morgan, Sugar, Sugar/Cane and Beet Share the Same Chemistry but Act Differently in the Kitchen, S.F. GATE (Mar. 31, 1999, 4:00 AM), http://www.sfgate.com/ news/article/SUGAR-SUGAR-Cane-and-beet-share-the-same-2939081.php [http://perma.cc/F4CDN9YB].

171. This is not to say that sugar is safe for everyone or at any all level of consumption. See generally Beyranevand, supra note 148, at 3 (discussing studies linking sugar to a variety of health problems).

172. HFCS is described in FDA documents as:

a sweet, nutritive saccharide mixture containing approximately $52 \%$ (dry weight) glucose, $43 \%$ (dry weight) fructose, and 5\% (dry weight) other saccharides. It is prepared as a clear aqueous solution from high dextrose equivalent corn syrup hydrolystate by partial enzymatic conversion of glucose (dextrose) to fructose using an insoluble glucose isomerase enzyme preparation.

Proposed Affirmation of GRAS Status of High Fructose Corn Syrup, 53 Fed. Reg. 44,904, 44,904 (Nov. 7, 1988) (to be codified at 21 C.F.R. pt. 182, 184). A more accessible description of the process is that "[t]o make high fructose corn syrup, it is necessary to (1) extract the starch from corn, (2) treat the starch with an enzyme to break it into glucose, and (3) treat the glucose with another enzyme to turn about half of it into fructose." Marion Nestle, FDA Changes Mind; Says HFCS Is Natural After All, Food PoL., (Aug. 8, 2008), http://www.foodpolitics.com/2008/08/fdachanges-mind-says-hfcs-is-natural-after-all/ [http://perma.cc/US3Q-4GCM].

173. The FDA denied the Corn Refiners Association's petition to allow the listing of HFCS on ingredient lists as "corn sugar" for this reason. Letter from Michael M. Landa, Dir., Ctr. for Food Safety \& Applied Nutrition, to Audrae Erickson, President, Corn Refiners Ass'n (May 30, 2012), 
Differentiating ingredients from additives on the basis of natural, as opposed to artificial origin, is consistent in principle with the analysis of the Fifth Circuit in United States v. Anderson Seafoods. ${ }^{174}$ This case, decided under the FDCA's adulteration provision ${ }^{175}$ rather than the food additive provision, ${ }^{176}$ distinguished the statutory standards for producer liability for poisonous or deleterious substances "added" to food from such substances present in food but "not added" by human action. The Fifth Circuit noted that this distinction "comes from the adulterated food provisions of the original Food, Drug, and Cosmetic Act of 1906," whose "legislative history shows that 'added' meant attributable to acts of man and 'not-added' meant attributable to acts of nature." 177 As examples, the court cited as "added things" the "lead in coloring agents or caffeine in CocaCola[,]" while "not-added things" included the "oxalic acid in rhubarb or caffeine in coffee." "178

In sum, the definition of "additives" was clearly intended to match the breadth of new substances and processes being introduced into the food supply. The use of the substance must be intended, but its result need only be reasonably expected. Use may be direct or indirect and may occur at any stage of the food production process from farm to retailer. The inclusion of a process - irradiation - suggests a willingness to reach aspects of food technology that otherwise have little to do with the concept of "substances" added to foods. So described, the definition of "additives" seems broadly aimed at industrial foods. Its language does not fit well with traditional ingredients used by home cooks. Because the statute's literal terms encompass traditional ingredients, this Article proposes that it be amended to clarify that "additives" applies only to non-traditional, non-naturally occurring substances. In short, traditional ingredients are "food." "Additives" are not "food" for purposes of regulatory treatment, even when they are incorporated or migrate into articles used for food.

\section{Safety}

Food additive legislation was premised on fears about the safety of new chemical substances being added to processed and packaged foods. Under

available at http://www.fda.gov/AboutFDA/CentersOffices/OfficeofFoods/CFSAN/ CFSANFOIAElectronicReadingRoom/ucm305226.htm [perma.cc/2ASK-U2CX] (denying the Corn Refiners Association's citizen petition); see also Candice Choi, High Fructose Corn Syrup: FDA Rejects 'Corn Sugar' as New Name, Huffington Post (May 31, 2012, 8:38 AM), http://www. huffingtonpost.com/2012/05/31/high-fructose-corn-syrup-corn-sugar_n_1558615.html [http://perma.cc/A32S-HKLU].

174. 622 F.2d 157 (5th Cir. 1980).

175. 21 U.S.C. $\S 342(a)(1)(1975)$.

176. $I d . \S 348$.

177. Anderson Seafoods, 622 F.2d at 159.

178. Id. at 160. The Fifth Circuit held that, "where some portion of a toxin present in food has been introduced by man, the entirety of that substance present in the food will be treated as an added substance." Id. at 161 . 
existing law, the GRAS exception depends on a demonstration that a particular substance is safe for its intended use. ${ }^{179}$ Thus, the notion of "safety" of the substance itself is critical to the statutory scheme under which articles demonstrated to be safe are exempt from pre-market approval. The FDA's recent focus, however, appears to have shifted to the general recognition, or "common knowledge" element, of GRAS status. Under the watered-down evidentiary requirements of the current notification procedure, an assertion of "common knowledge" may be more akin to a shared belief — or hope — of safety. The 1997 Notice of Proposed Rule "emphasiz[es]" the FDA's view that "a GRAS substance is distinguished from a food additive by the common knowledge about the safety of the substance for its intended use rather than by what the substance is." 180 This posture is inconsistent with the statute's emphasis on safety, which is to be evaluated by analysis of what the substance is, how it is being used, and how it affects the body. To account for the particular dangers additives present, "safety" must be understood broadly.

"Safe" is defined in section 321(u) for purposes of the food additive provisions as "ha[ving] reference to the health of man or animal." "Health" is not defined in the statute. The Centers for Disease Control \& Prevention ("CDC") defines "health" as "[a] state of complete physical ... well-being and not just the absence of sickness or frailty." "182 Though some question this definition as too narrow, it is nearly contemporaneous with the 1958 Act and thus serves as a reasonable proxy for the health considerations Congress may have had in mind at the time. ${ }^{183}$ The 1958 Senate Report said this about safety:

Safety requires proof of a reasonable certainty that no harm will result from the proposed use of the additive ... In determining the safety of an additive, scientists must take into consideration the cumulative effect of such additive in the diet of man or animals over their respective life

179. 21 U.S.C. $\S 321$ (2012).

180. Substances Generally Recognized as Safe, 62 Fed. Reg. 18,938-01, 18,940 (proposed Apr. 17, 1997) (to be codified at 21 C.F.R. pt. 170) (emphasis added). The proposed rule indicates that the FDA's focus will be on "identifying the types of technical evidence of safety that could form the basis of a GRAS determination." Id. (emphasis added).

181. 21 U.S.C. $\S 321$.

182. Definitions, Ctrs. FOR Disease Control \& Prevention, http://www.cdc.gov/ socialdeterminants/Definitions.html [http://perma.cc/973R-JY3K] (last updated Mar. 21, 2014).

183. The 1958 enactment of the "Delaney Clause," which provides that "no additive shall be deemed to be safe if it is found to induce cancer when ingested by man or animal" indicates Congress's concern with a particular disease then much in the news, but does not negate the overall notions of health and safety described above. Food Additives Amendment of 1958, Pub. L. No. 85929, 72 Stat. 1784 (codified as amended in scattered sections of 21 U.S.C.). To the contrary, the Senate Committee comment on this clause states: "[I]n our opinion the bill is aimed at preventing the addition to the food our people eat of any substances the ingestion of which reasonable people would expect to produce not just cancer but any disease or disability." S. REP. No. 85-2422, at 5310 (1958). 
spans together with any chemically or pharmacologically related substances in such diet. Thus, the safety of a given additive involves informed judgments based on educated estimates ... of the anticipated ingestion of an additive . . . under likely patterns of use ... In determining the safety of an additive, the Secretary would have to consider not only the food in which the additive is directly added, but also other foods derived from such foods. ${ }^{184}$

This passage's emphasis on "reasonable certainty that no harm will result" indicates that Congress took a comprehensive, long-term view of health, as "harm" is much broader than specific, acute illness. The requirement that safety determinations focus on cumulative exposure over a lifetime, taking account of the presence of the same or a similar substance in other food products and of typical dietary patterns, corroborates the view that Congress equated safety with overall health. This broad understanding is necessary in view of the ubiquity of food additives. As long ago as 1980, GAO noted that

the public's exposure to [food additives] has greatly increased since the 1958 amendment . . . because their use has allowed the development of convenience foods demanded by the present day eating habits of most Americans . . . Virtually everyone consumes food which contains additives, and that consumption can extend over a lifetime. Even small risks associated with these substances are magnified when exposure extends over long periods. ${ }^{185}$

The Pew Report of 2013 noted that the "American diet is dramatically different today compared with what it was when Congress enacted the Food Additives Amendment of 1958," focusing on the fact that "our food supply is more diverse and more processed" and thus uses more chemical additives. ${ }^{186}$

The FDA's reversal of position with respect to several additives, once considered GRAS substances, illustrates the difficulty of evaluating safety. The GAO's 1980 Report details the history of three "widely used" substances that were once classified as GRAS or prior-sanctioned substances but whose safety

184. S. REP. No. 85-2422, at 5305. The FDA adopted this approach nearly verbatim when it defined "safe" or "safety." 21 C.F.R. § 170.3(i) (2015). By contrast, the 1938 Act was passed in the aftermath of the 1937 scandal in which "a legally marketed toxic elixir killed 107 people, including many children," suggesting that at least the immediate motivation of the 1938 Act was sudden illness or death as a result of one-time or short-term exposure to a dangerous substance. See Legislation, FOOD \& DRUG ADMIN., http://www.fda.gov/regulatoryinformation/legislation/ default.htm [http://perma.cc/7UWR-HWA9] (last updated July 7, 2015).

185. Gen. AcCounting OfFICE, supra note 94, at 22. In the same report, GAO reported that Americans consumed about 139 pounds of additives per year, of which about nine pounds are chemical additives (as opposed to sugar, salt, and the like). Id. at 2. Recent figures are consistent. See Factsheet for Consumers, U. R.I. (May 30, 2012), http://web.uri.edu/foodsafety/category/ factsheets-for-consumers/page/2/ [http://perma.cc/PTP2-4VUV].

186. Pew Charitable Trs., supra note 24 , at 1. 
was called into question on the basis of new scientific evidence or review of existing data. ${ }^{187}$ More recently, the FDA changed course with respect to trans fats it had recognized as GRAS beginning in the 1970 s. ${ }^{188}$ Determining safety is not a simple process. The scientific evidence is often mixed and the calculus of safety requires complicated predictions about how both the food supply and the typical American diet will change over a lifetime. In the meantime, medical understanding of various diseases evolves and dietary recommendations change. Difficult or not, the FDCA mandates a focus on actual evidence of safety.

\section{E. Summary}

"Food" is interpreted broadly under the FDCA so as to extend the Act's protections to all items Americans consume for flavor, energy, or nutrition. Any substance that becomes part of a food is a "component" of the food. Under existing law, components of food are "food" for regulatory purposes. ${ }^{189}$ Under the proposed definitions, by contrast, "components" is an umbrella term that includes both "ingredients" (which are food) and "additives" (which are not food). These two categories would be sharply differentiated. "Ingredients" would be defined as naturally occurring substances, traditionally used in foods prepared in the home. "Additives," on the other hand, would be defined as artificial or synthetic substances available to and used by food producers. The concept of safety with regard to such substances would take into account, as current law already mandates, cumulative exposure in the typical diet and both short-term and long-term consequences of consumption.

In short, additives warrant stricter treatment than do naturally-occurring, traditional foods and food ingredients. Congress's 1958 scheme makes sense even if some of the details raise difficulties. But present practice departs markedly from that scheme. If the 1958 additives regime calling for pre-market approval is unworkable, more modest steps may partially fill the safety gap that currently exists. This Part has proposed new definitions of key terms. The next two Parts consider potential reforms that could be constructed on the basis of the proposed definitions.

\section{The Mechanism for Differentiating Regulation of "Food” FROM THAT OF "ADDITIVES"}

Statutory text and legislative history make clear that ordinary "food" and traditional "food ingredients" were to be sharply differentiated from new, chemical "additives." The safety of additives is never presumed; it must be

187. Gen. AcCounting OfFICE, supra note 94, at 12-15 (discussing saccharin, cyclamate, and nitrite).

188. FDA Cuts Trans Fat in Processed Foods, Food \& DRUG AdmIn., http://www.fda.gov/ ForConsumers/ConsumerUpdates/ucm372915.htm [http://perma.cc/FZE7-B86J] (last updated June 16, 2015).

189. 21 U.S.C. $§ 321$ (2012). 
established by the proponent. ${ }^{190}$ This Article argues that traditional ingredients are "food" and not "additives." If traditional ingredients are not within the definition of "additives," then there is no need for a statutory provision excluding them from that category. If that proposal is not adopted, however, some mechanism is required to differentiate the treatment of food and additives.

The 1958 Act's solution is the GRAS exception. Congress provided two avenues to GRAS status: the "common use" and "scientific procedures" routes. ${ }^{191}$ The existing "common use" route to GRAS status should be understood to apply only to traditional food ingredients, while the "scientific procedures" route applies to food additives as redefined herein: substances of non-natural origin added intentionally to food to achieve a particular functional effect. Linking regulatory treatment to safety makes sense, but the safety provision should stand on its own, not as an exception to the definition of "food additives." This Article proposes to eliminate the existing GRAS exception and replace it with two distinct statuses, the former denominated as Commonly Recognized as Safe ("CRAS") and the latter as Scientifically Recognized as Safe ("SRAS"). CRAS status would apply to traditional food ingredients if they remain within the definition of additives. SRAS status would apply to artificial or chemical additives.

\section{A. Common Use in Food Providing Historical Evidence of Safety}

Traditional food ingredients were not intended to be regulated as anything other than "food." 192 Congress recognized that its broad definition of "additives" would apply literally to traditional food ingredients. ${ }^{193}$ To avert the burden of scientifically establishing safety of food ingredients that had already long been in use, Congress chose the mechanism of an exception from the definition of "additives." 194 Thus, "substance[s] used in food prior to January 1, 1958" that had been "adequately shown" through "experience based on common use in food" to be safe for human consumption were exempted from treatment as "additives." 195

190. Substances Generally Recognized as Safe, 62 Fed. Reg. 18,938-01, 18,939 (proposed Apr. 17, 1997) (to be codified at 21 C.F.R. pt. 170).

191. Food Additives Amendment of 1958, Pub. L. No. 85-929, 72 Stat. 1784 (codified as amended in scattered sections of 21 U.S.C.).

192. For a recent argument that traditional ingredients now linked to health problems should be so regulated, see Beyranevand, supra note 148, at 919.

193. Substances Generally Recognized as Safe, 62 Fed. Reg. at 18,939.

194. See S. ReP. No. 85-2422 at 5301 (1958) (describing as a "flaw in existing law" a "provision which has inadvertently served to unnecessarily proscribe the use of additives that could enable ... the nation to make use of the advances in technology calculated to increase and improve our food supplies" and advocating that "existing law should be changed to permit the use of such additives ... which may benefit our people and our economy when the proposed usages of such additives are in amounts accepted by the [FDA] as safe").

195. 21 U.S.C. $\S 321(\mathrm{~s})$. 
The FDA and the food industry originally understood GRAS as a narrow exception, reachable only as a result of common knowledge based on pre-1958 use in food or through rigorous scientific procedures. Shortly after the FDA published regulations on GRAS status, a food industry lawyer described the agency's approach as "believ[ing] that some GRAS substances are more GRAS than others." ${ }^{196}$ Specifically,

[t]he grandfather clause was to be considered as obviously applicable to a select group of substances which . . . was identified as . . those substances of natural biological origin consumed for nutrient properties in the United States prior to January 1, 1958, without detrimental effect ... including such of those substances modified by conventional processing as practiced prior to January $1,1958 .{ }^{197}$

Among the FDA's "categories of so-called lesser GRAS substances" were "those not of natural biological origin, even if nature-identical." 198 For these substances, "the FDA's regulation required [notice-and-comment rulemaking] and a finding of convincing evidence of their general recognition of safety." 199 A later commentator described the FDA's 1971 GRAS regulation as "reflecting FDA's view that foods of biological origin were different, for GRAS purposes, from other foods. ${ }^{200}$ According to Frederick Degnan, the FDA in 1958 "took the position that any substance added to food and having no history of common use as a food ingredient [] 'should be regarded' as a substance that is not GRAS."201 At the time, many thought that GRAS status was reserved for substances used safely in food before $1958 .{ }^{202}$ But the history-of-use route to GRAS status was soon applied to substances first introduced after $1958 .^{203}$

The FDCA is a consumer protection statute ${ }^{204}$ aimed at ensuring both the safety of food ${ }^{205}$ and the "fair dealing" that results when consumers get what they

196. Roger D. Middlekauff, Food Safety Review - New Concepts for GRAS, 30 Food DruG Cosm. L.J. 288, 291 (1975).

197. Id.

198. Id.

199. Id. (disputing the FDA's categorization and treatment of GRAS substances in this manner).

200. Degnan, supra note 57, at 570 (arguing the FDA's approach was an overly "formal, rigid categorization").

201. Id. at 563 (emphasis added) (citing proposed 21 C.F.R. $\S 121.3$ (1958)).

202. Id. at 570 .

203. See Gen. Accounting Office, supra note 94, at iii (reporting that despite belief that the history-of-use route was applicable only to substances in use before 1958, "most of the 800 [substances designated by their proponents as GRAS] were first used in food after 1958 and thus their safety should be based on scientific evidence" rather than history-of-use).

204. See Martha Dragich, Do You Know What's on Your Plate?: The Importance of Regulating the Processes of Food Production, 28 J. EnVTL. L. \& LiTig. 385, 406-07 (2013) (citing legislative history and cases).

205. Young v. Cmty. Nutrition Inst., 476 U.S. 974, 976 (1986). 
are paying for. ${ }^{206}$ Invoking "experience" and "common use"207 as the basis for excluding traditional food ingredients from strict regulation as "additives"208 fits comfortably within the concept of "general recognition" of safety by ordinary consumers. For clarity, recognition of safety based on a history of common use in food should be known as CRAS.

The term "CRAS substance" should be reserved for traditional food ingredients or substances of natural origin whose safety is demonstrated by a history of safe use in food prior to 1958. A separate status is needed for nonnaturally occurring substances and for substances introduced into the food supply after 1958. As the GAO argued in 1980, "[h]istory of use is generally no longer considered a sound basis for safety judgments" ${ }^{\text {"209 }}$ and

continued acceptance of history of use as the sole basis for safety determinations does not seem appropriate in view of current concerns about additive safety and advances in safety evaluation methods. The need for legislative authority to require that substances [with a history of use in food] be subjected to scientific tests is demonstrated by safety questions about such substances as saccharin, cyclamate, and nitrite. ${ }^{210}$

GAO argued that requiring scientific evidence for a GRAS designation of additives first used after 1958 is not sufficient; rather, "the law should be amended to require FDA to review safety evidence for all GRAS substances," including those with a period of (apparently) safe use. ${ }^{211}$

\section{B. Scientific Procedures Providing Credible Evidence of Safety}

The 1958 Act also contemplates that some chemical additives might be recognized as safe by another criterion: scientific procedures providing credible evidence of safety. ${ }^{212}$ The GRAS exception thus encompasses substances "recognized, among experts qualified by scientific training and experience to evaluate [their] safety, as having been adequately shown through scientific procedures" to be safe. ${ }^{213}$ It is unclear how broad this category was thought to be or what kinds of substances were included in it. ${ }^{214}$ There is no suggestion, however, that additives entering the marketplace after 1958 could achieve GRAS

206. 62 Cases of Jam v. United States, 340 U.S. 593, 594 (1951).

207. 21 C.F.R. $\S 170.30(c)(1)(2015)$.

208. Id. $\S 170.3(\mathrm{e})(1)$.

209. Gen. Accounting Office, supra note 94, at 10; id. at 11 (citing a report by the Federation of American Societies for Experimental Biology, stating that a "long history of use of a food additive [referring to artificial or synthetic substances] without evident harm resulting ... alone has limited value in providing adequate assurance of the safety of lifetime consumption”).

210. Id. at 21 .

211. $I d$.

212. See 21 U.S.C. $\S 321$ (s) (2012), as interpreted by the FDA in 21 C.F.R. $\S 170.30$ (2015).

213. 21 U.S.C. $\S 321(\mathrm{~s})$.

214. Cf. Degnan, supra note 57, at 554-66. 
status by any mechanism other than scientific procedures. ${ }^{215}$

Moreover, the implementing regulations are very specific about a number of aspects of achieving GRAS status. The fact that a substance is GRAS for use in one food "does not make the substance GRAS for another food or use." 216 The statute's emphasis on scientific expertise and rigorous procedures of proof for each proposed use illustrates the sharp distinction Congress had in mind between unfamiliar chemical additives and traditional food ingredients. "General recognition" of safety has been interpreted strictly by FDA and courts as requiring solid scientific evidence, ${ }^{217}$ disseminated through credible channels, ${ }^{218}$ and having achieved a fairly high degree of consensus as to safety. ${ }^{219}$ A nearly contemporaneous commentary suggested that the 1958 Act was carefully worded to require that an expert be qualified to evaluate the particular additive in question, not merely to evaluate food additives in general. ${ }^{220}$

215. 21 C.F.R. $\S 170.30$ (a).

216. ForTin, supra note 9, at 268 (citing United States v. An Article of Food, 752 F.2d 11 (1st Cir. 1985) (concluding that the "sanction permitting very limited use of potassium nitrate in meats cannot be construed to sanction use of the same substance for an altogether different purpose in beverages.")); see also General Recognition of Safety and Prior Sanction for Food Ingredients, 39 Fed. Reg. 34,194-01, 34,194 (proposed Sept. 23, 1974) (to be codified at 21 C.F.R. pt. 121) (noting necessity of review for GRAS substances "for which new processing methods have been introduced since 1958 or . . . other significant alteration of composition has been made"). FDA further noted that

[i]n the past, it has been too often assumed that a GRAS substance may be used in any food, at any level, for any purpose. As a result, the uses of some GRAS food ingredients have proliferated to the point where their GRAS status has been brought into serious question.

Id. at 34,194-95.

217. See Degnan, supra note 57, at 570-71 (citing Weinberger v. Hynson, Westcott \& Dunning, Inc., 412 U.S. 609 (1973)) ("[The] scientific inquiry regarding the effectiveness of GRAS drugs had to conform to the requirements of new drugs."). The FDA subsequently concluded that "general recognition of safety on the basis of scientific procedures under section [321(s)] would require the same quantity and quality of evidence as required for approving the safety of a food additive under section [348]." Id. at 571.

218. 21 C.F.R. § 170.30(b); see also Substances Generally Recognized as Safe, 62 Fed. Reg. 18,938-01, 18,942-43 (proposed Apr. 17, 1997) (to be codified at 21 C.F.R. pt. 170) (discussing scientific procedures).

219. Substances Generally Recognized as Safe, 62 Fed. Reg. at 18,939 (stating that consensus of expert opinion, but not unanimity, is required to establish GRAS status); id. at 18,941 (stating that pursuant to the requirement of "consensus," FDA will "evaluate a single published report questioning the safety of use of a substance ... rather than conclude that such a report automatically disqualifies the substance from satisfying the GRAS standard").

220. Joseph D. Becker, The Gras Clause of the Food-Additives Amendment, 15 Food Drug Cosm. L.J. 444, 444 (1960) (focusing on the phrase "among experts qualified by scientific training and experience to evaluate its safety," comparing this phrase to different wording in sections relating to new drugs and pesticide chemicals, and drawing the conclusion that to qualify as an 
The FDA's recent practice, however, departs from the rigor of this framework. ${ }^{221}$ The existing GRAS exception has nearly overtaken the category of additives, as industry self-determination of GRAS status is now the norm. ${ }^{22}$ Thus, most substances that meet the definition of "additives" before applying the GRAS exception come to market never having been examined for safety by the FDA via the food additive petition process Congress mandated for most additives. $^{223}$

It is futile to argue that the GRAS exception should be understood today as narrowly as it might have been soon after passage of the 1958 Act ${ }^{224}$ But the definition-with-exception formulation in section 321(s) could be rewritten to restore the notion that the GRAS exception excludes substances from the definition of food additives only in narrow, well-delineated circumstances. Under the proposal, the GRAS exception of current law would no longer exist. All nonnaturally occurring chemical substances not traditionally used in food are defined as additives. As such, they are subject to premarket approval by the FDA unless they are considered safe under 21 U.S.C. $§ 321$ for the particular use. Substances demonstrated by scientific evidence to be safe would be known as SRAS (Scientifically Recognized as Safe). The exacting standards of current law regarding scientific procedure ${ }^{225}$ should remain in place and be observed in practice. In addition, as elaborated in the next part, SRAS status should be made contingent upon producers' compliance with notification, monitoring, and reporting requirements.

\section{Summary}

This Article proposes to replace the current GRAS exception with another mechanism for differentiating the regulatory treatment of "food" from that of "additives." A new, freestanding provision would establish two ways to demonstrate that an additive is safe. As Part II argued, traditional food ingredients are not "additives." But if traditional ingredients continue to be treated as additives, their safety would be established through a history of common use in food. "Additives" are defined on the basis of their non-natural origin. Artificial and synthetic additives may be demonstrated to be safe only by scientific procedures. Absent such showing, additives are subject to premarket

expert under the 1958 Act, a scientist must "have studied the particular additive in question or the class of additives to which the particular additive belongs").

221. Pew Charitable TrS., supra note 24, at 9-10 (discussing problems in the current scientific procedure regime); $i d$. at 13 (discussing the need for scientific consensus regarding safety).

222. Hutt \& Merrill, supra note 23, at 397; Pew Charitable TrS., supra note 24, at 1.

223. Pew Charitable Trs., supra note 24 , at 1.

224. Cf. Gen. Accounting Office, supra note 94, at 21 (calling for legislation to eliminate GRAS exception in favor of applying food additive provisions to "all substances added directly to food"). This proposal apparently never received serious consideration.

225. 21 C.F.R. $\S 170.30$ (2015). 
review for safety.

\section{The Responsibilities of FDA And Producers for the SAFEty of Food AdDitives}

As noted, most substances defined as food additives escape regulation as such by claiming to meet the existing GRAS exception. ${ }^{226}$ In other words, most substances avoid the formal FDA pre-market approval process by which their safety would be reviewed rigorously. Instead, these substances currently reach the market under the FDA's 1997 Proposed Rule allowing voluntary notification to FDA of the producer's GRAS self-determination. ${ }^{227}$ Even when notification occurs, it is accompanied only by summary data and the FDA undertakes no substantive review. ${ }^{228}$

A frequent criticism of the FDA's oversight of food additives is that under the voluntary notification procedure the agency lacks even a complete list of GRAS substances, let alone comprehensive data about their use. ${ }^{229}$ Pew reports that "more than 10,000 additives" are used in food, of which the "FDA has not reviewed the safety of about 3,000." ${ }^{\prime 230}$ The General Accounting Office concluded in 2010 that "because companies are not required to provide information to FDA regarding their GRAS determinations," ${ }^{231}$ FDA officials "cannot estimate the number of determinations that occur about which they are not notified." ${ }^{\prime 232}$ Hence, GAO concluded that "FDA has [little] awareness of substances in the nation's food supply and [little] knowledge of the potential cumulative dietary exposure of GRAS substances. ${ }^{\prime 33}$ These facts prompted the 2013 Pew Charitable Trusts Report to conclude:

[I]t is essentially impossible for the agency to connect an additive to a health problem when it has . . not been notified about . . chemicals currently used in food, not been informed of actual usage for all chemicals, [and] not been alerted to studies that suggest previously

226. Pew Charitable Trs., supra note 24, at 1.

227. Substances Generally Recognized as Safe, 62 Fed. Reg. 18,938-01, 18,945-53 (proposed Apr. 17, 1997) (to be codified at 21 C.F.R. pt. 170).

228. Id. at 18,947 .

229. See Hutt \& Merrill, supra note 23, at 410 (describing President Nixon's order of a GRAS list); GEN. ACCOUNTING OFFICE, supra note 6, at 12-14 (documenting the FDA's continuing failure to maintain a complete GRAS inventory); see also Guidance for Industry: Frequently Asked Questions About GRAS, FOOD \& DRUG ADMIN., http://www.fda.gov/Food/ GuidanceRegulation/GuidanceDocumentsRegulatoryInformation/IngredientsAdditivesGRASPa ckaging/ucm061846.htm [http://perma.cc/T3CU-ECBZ] (last updated Apr. 14, 2015) (recognizing that the FDA does not keep a complete list of GRAS substances).

230. Pew Charitable Trs., supra note 24, at 1, 5.

231. Gen. Accounting OfFice, supra note 6, at 12.

232. Id. at 13 .

233. Id. 
unknown potential health effects. ${ }^{234}$

It is equally "impossible [even] for informed consumers to protect themselves from the harmful chemicals" used in food when neither producers nor the FDA inform them of the identity or uses of such substances. ${ }^{235}$

The FDA's current inability to oversee the safety of food additives is amenable to a solution that promises significant benefit to consumers at a relatively low cost to producers and regulators. Simply put, the FDA should promulgate a regulation requiring producers to notify the FDA of all SRAS substances and the self- (or industry-) determinations of their safety before introducing them into the market. Producers ought to be required to monitor on an ongoing basis the safety of all substances in use in their products and to report credible adverse information to the FDA as that information develops. These requirements are comprehended within the authority of existing statutory provisions, which assign to producers the burden of establishing the safety of substances they use in food. The steady decline in the FDA's enforcement of the statute does not write these provisions out of the code. The proposed notification, monitoring, and reporting requirements fall far short of the FDCA's mandate but may restore some measure of oversight of food additives by providing comprehensive information about their use and a basis for responding to safety concerns as they arise.

\section{A. Duty to Notify FDA of All Additive Use and SRAS Self-Determinations}

As a first step, the August 2016 version of the 1997 Proposed Rule on GRAS Notification should mandate producer notification to the FDA of all new additives and their SRAS determinations. ${ }^{236}$ This mandatory notification requirement avoids two obstacles frequently identified as blocking the path to more robust oversight of food additives: the burden on the FDA's resources ${ }^{237}$ and the delay imposed on producers who wish to get new products to market quickly. ${ }^{238}$ The FDA is already responsible for the safety of the food supply,

234. Pew Charitable Trs., supra note 24, at 7.

235. See Petition Asks FDA to Ban 8 Synthetic Flavorings Now Considered GRAS, FoOD SAFETY NEws (June 11,2015), http://www.foodsafetynews.com/2015/06/petition-asks-fda-to-ban8-synthetic-flavorings-now-considered-gras/\#.Va_rfvlVikp [perma.cc/ZV2H-G9U3] (quoting a statement from the Natural Resources Defense Council). The GAO identified similar concerns as early as 1980. See GeN. ACCOUNTING OfFICE, supra note 94, at 22.

236. This duty does not apply to CRAS substances. If the statutory reference to "experience based on common use in food" is understood to refer only to substances used in food prior to 1958 , new CRAS determinations are unlikely. 21 C.F.R. § 170.30(c)(1) (2015).

237. The FDA flatly announced that it "does not intend to conduct its own detailed evaluation of the data that the notifier relies on to support a determination that a use of a substance is GRAS or to affirm that a substance is GRAS for its intended use." Substances Generally Recognized as Safe, 62 Fed. Reg. 18,938-01, 18,941 (proposed Apr. 17, 1997) (to be codified at 21 C.F.R. pt. 170).

238. The FDA's Notice of Proposed Rule states that the "proposed notice is simpler than [the 
including food additives. Mandatory rather than voluntary notification would increase the FDA's workload to some degree difficult to calculate in the absence of information about how many substances currently go to market without notification to the FDA. Under the 1997 Proposed Rule, the FDA reviews not the scientific evidence for proof of safety, but rather the documentation submitted for sufficiency under the statutory criteria for notification. ${ }^{239}$ This is a cursory review, to be completed within ninety days. ${ }^{240}$ Ideally, FDA's review would be focused more closely on the actual safety of the substance under review. ${ }^{241}$ But until wholesale reform of the FDA's process is undertaken, there is value in requiring notification to the FDA of all substances in the food supply. That way, both the FDA and consumers have a place to start in investigating potential problems.

Likewise, producers are already liable for the safety of products they send into the market and are responsible, at least in theory, for determining in advance the safety of food additives they use. The 1997 proposed notification rule provides that "any person" who wishes to notify FDA of a claim that a particular use of a substance is exempt from the statutory premarket approval requirements based on the notifier's determination that such use is GRAS ${ }^{242}$ must submit specific information identifying the substance, discussing the conditions of use and providing a "detailed summary of the basis for the notifier's determination that a particular use of the notified substance is . . GRAS." ${ }^{243}$ The requirement

former voluntary] GRAS affirmation petition and therefore conceivably would provide an incentive for manufacturers to inform FDA of their GRAS determinations." Id. The FDA argues this is so because the

GRAS affirmation involves the resource-intensive rulemaking process, including: (1) Publishing a filing notice in the Federal Register; (2) requesting comment on the petitioned request; (3) conducting a comprehensive review of the petition's data and information and comments received to the filing notice to determine whether the evidence establishes that the petitioned use of the substance is GRAS; (4) drafting a detailed explanation of why the use is GRAS (as opposed to simply being safe); and (5) publishing that explanation in the Federal Register. FDA believes that, in practice, this resource-intensive process deters many persons from petitioning the agency to affirm their independent GRAS determinations.

Id.

239. Id. (stating that "the agency intends to evaluate whether the notice provides a sufficient basis for [the notifier's] GRAS determination" and does not "raise[] issues that lead the agency to question whether use of the substance is GRAS). The FDA "does not intend to conduct its own detailed evaluation of the data" submitted. Id.

240. Id. at 18,950 .

241. See supra Part II.D.

242. Substances Generally Recognized as Safe, 62 Fed. Reg. at 18,945-46.

243. Id. at 18,961. More specifically, the 1997 proposed regulation $170.36(\mathrm{c})(1)$ requires that a notifier submit:

(ii) The common or usual name of the substance that is the subject of the GRAS

exemption claim (i.e., the "notified substance"); 
of a "detailed summary" implies that the notifier must be able to produce full data upon request. The 1997 notification procedure makes this suggestion explicit a few paragraphs later, stating that

any person who determines that a substance is GRAS should have assembled and evaluated the evidence that forms the basis of such a determination, regardless of whether the person subsequently notifies the agency about the claim. Therefore, FDA believes that the burden to the notifier of the proposed rule is the minimal burden of maintaining the

(iii) The applicable conditions of use of the notified substance, including the foods in which the substance is to be used, levels of use in such foods, and the purposes for which the substance is used, including, when appropriate, a description of the population expected to consume the substance...

(2) Detailed information about the identity of the notified substance, including, as applicable, its chemical name, Chemical Abstracts Service (CAS) Registry Number, Enzyme Commission number, empirical formula, structural formula, quantitative composition, method of manufacture (excluding any trade secrets and including, for substances of natural biological origin, source information such as genus and species), characteristic properties, any content of potential human toxicants, and specifications for food-grade material; . . . and

(4) A detailed summary of the basis for the notifier's determination that a particular use of the notified substance is exempt from the premarket approval requirements of the act because such use is GRAS ...

(i) For a GRAS determination through scientific procedures, such summary shall include:

(A) A comprehensive discussion of, and citations to, generally available and accepted scientific data, information, methods, or principles that the notifier relies on to establish safety, including a consideration of the probable consumption of the substance and the probable consumption of any substance formed in or on food because of its use and the cumulative effect of the substance in the diet, taking into account any chemically or pharmacologically related substances in such diet;

(B) A comprehensive discussion of any reports of investigations or other information that may appear to be inconsistent with the GRAS determination; and

(C) The basis for concluding, in light of the data and information described under paragraphs (c)(1), (c)(2), (c)(3), (c)(4)(i)(A), and (c)(4)(i)(B) of this section, that there is consensus among experts qualified by scientific training and experience to evaluate the safety of substances added to food that there is reasonable certainty that the substance is not harmful under the intended conditions of use.

Id. 
information. Such preservation of the data and information that are the basis for the GRAS determination also represents prudent practice for those who claim an exemption from a statutory requirement. ${ }^{244}$

If the additive turns out not to be safe, the producer has only its own determination of safety to fall back on. Producers who have relied on weak or incomplete evidence, or on the opinions of experts whose analysis is compromised by conflicts of interest, are subject to liability for selling adulterated food if a safety problem develops. ${ }^{245}$ The proposed mandatory notification procedure does not increase producers' risk compared to the 1997 procedure. $^{246}$

Granted, the current notification procedure is voluntary and producers have not always used it. The FDA, however, clearly intended that it would be widely used. The 1997 Notice of Proposed Rule states:

the proposed notice is simpler than a [voluntary] GRAS affirmation petition and therefore conceivably would provide an incentive for manufacturers to inform FDA of their GRAS determinations. This would result in increased agency awareness of the composition of the nation's food supply and the cumulative dietary exposure to GRAS substances." ${ }^{247}$

Increasing the FDA's awareness of additives in the food supply remains the goal, but voluntary notification does not achieve it. Because producers see little value in the voluntary procedure ${ }^{248}$ mandatory notification is necessary.

Producers who have legitimately determined that the substances they are using are safe have already gathered the required information, even if they have chosen not to notify the FDA of their GRAS self-determinations in the past. Their potential liability is simply too great otherwise. ${ }^{249}$ Any food containing an

244. Id. at 18,947 .

245. The burden of proof of adulteration of food falls (as in any personal injury or wrongful death litigation) on the person alleging adulteration - an advantage for the producer. The burden of proof of the safety of a food additive, however, is on the proponent of the additive. See United States v. An Article of Food, 752 F.2d 11, 15 (1st Cir. 1985). Thus, producers who self-determine GRAS status on the basis of weak evidence of safety expose themselves to litigation risks in addition to FDA-imposed sanctions. $C f$. Noah \& Merrill, supra note 48, at 363-64 (stating that "making a unilateral GRAS determination [under the 1997 proposed rule] carries regulatory risk").

246. Substances Generally Recognized as Safe, 62 Fed. Reg. at 18,947.

247. Id. at 18,941 .

248. See supra Part I.B.

249. Cf. Substances Generally Recognized as Safe, 62 Fed. Reg. at 18,958 (discussing the pre1997 GRAS affirmation process as a baseline against which to measure the 1997 proposed rule). According to the FDA:

The benefit firms receive from participation in the [pre-1997] GRAS petition process appears to involve a reduction in the cost of marketing foods containing substances independently determined to be GRAS because FDA affirmation of GRAS status would 
unsafe additive is adulterated, ${ }^{250}$ its sale is unlawful, ${ }^{251}$ and the FDCA's various sanctions become available. ${ }^{252}$ Recalls of adulterated products are extremely costly. ${ }^{253}$ Thus, the added burden on producers under a mandatory notification regime is only preparation of the required documentation, not the conduct of the safety determination itself. As is true now under the 1997 Proposed Rule, ${ }^{254}$ this Article requires only summary documentation of the basis for the producer's GRAS self-determination. Producers may begin immediately upon notification to market their products; ${ }^{255}$ there is no agency evaluation process and no need to await the agency's response. ${ }^{256}$ The only change is that notification would be

likely facilitate marketing of such substances. Manufacturers of these foods and retail establishments buying these foods for subsequent resale to consumers may be reluctant to offer them for sale in the absence of assurance that FDA will not subsequently conclude that ingredients independently determined to be GRAS are unapproved food additives. If these substances were subsequently found not to be GRAS, any ensuing seizure of foods containing the unapproved food additive might damage the credibility of those manufacturers and retail establishments, and might lead to economic losses. If there were no process for agency GRAS affirmation, firms making independent GRAS determinations may attempt to substitute for GRAS affirmations by doing additional research, contracting with third party research organizations, or taking other steps to provide adequate assurances to other firms that FDA will probably not subsequently challenge their independent GRAS determinations.

Id. at 18,958 .

250. 21 U.S.C. $\S 342(a)(2)(C)(i)(2012)$.

251. Id. $\S 331$.

252. Id. $\S 332$ (injunction); id. $\S 333$ (civil and criminal penalties); id. $\S 334$ (seizure of goods); id. §335(a) (debarment).

253. See Report: Food Recalls Have Nearly Doubled Since 2002, Food SAFETy News (July 22, 2015), http://www.foodsafetynews.com/2015/07/report-food-recalls-have-nearly-doubled-since2002/\#.Va_cWflViko [perma.cc/79FZ-238E] (reporting an increase in the number of U.S. food recalls and stating that "[i]n more than half of those recalls, the process of recalling the food cost the affected company more than $\$ 10$ million. Some companies lost more than $\$ 100$ million in direct costs associated with the recalls.").

254. Substances Generally Recognized as Safe, 62 Fed. Reg. at 18,947.

255. The FDA's Notice of Proposed Rule states clearly that " $[\mathrm{u}]$ nder both the current and the proposed procedures, a manufacturer may market a substance that the manufacturer determines is GRAS without informing the agency or, if the agency is so informed, while the agency is reviewing that information." Id. at 18,941-42.

256. In the pre-1997 GRAS petition process, the FDA formally "affirmed" GRAS status of substances for which the petition demonstrated eligibility for GRAS status. 21 C.F.R. $\S$ 170.35(c)(1) (2015). Under the 1997 proposal, by contrast:

FDA would not be in a position to affirm a notifier's conclusion that a use of a substance is GRAS, and the rulemaking part of the GRAS affirmation process would not be necessary or appropriate. Rather, FDA would evaluate whether the notice provides a sufficient basis for the notifier's GRAS determination. For example, FDA may question the GRAS status of use of a substance if the information provided in a notice: (1) Does 
mandatory. Mandatory notification does not delay the producer's ability to begin realizing returns on its investment in the additive.

Any change from a voluntary process to a mandatory one is sure to be controversial no matter how slight the additional burdens. But that is not a reason to oppose this proposal. To begin with, the current statute obligates the FDA and producers to engage in a far more onerous approval process for food additives. ${ }^{257}$ Though there is some statutory ambiguity regarding whose prerogative it is to make GRAS determinations, ${ }^{258}$ Congress clearly contemplated FDA involvement and oversight, as the FDA itself seems to recognize ${ }^{259}$ Some argue, in fact, that the FDA's 1997 proposed rule is contrary to the statute ${ }^{260}$ and thus not entitled to Chevron deference. ${ }^{261}$ Moreover, one commentator argues that Congress recently strengthened the FDA's authority to compel notification: "FSMA grants FDA the authority to compel food facilities to provide full documentation of . . . GRAS determinations as part of their written food safety plans."262

not adequately establish technical evidence of safety; (2) is not generally available; (3) does not convince the agency that there is the requisite expert consensus about the safety of the substance for its intended use; or (4) is so poorly presented that the basis for the GRAS determination is not clear...

This narrow evaluation would facilitate FDA's rapid response to the notifier. Accordingly, under proposed $\S 170.36(\mathrm{e}), \mathrm{FDA}$ would respond to the notifier in writing within 90 days of receipt of the notice.

Substances Generally Recognized as Safe, 62 Fed. Reg. at 18,950-51.

257. This obligation is imposed indirectly. Under section 348 , food additives are deemed unsafe unless the FDA has by regulation prescribed the conditions under which they may safely be used. 21 U.S.C. $\S 348$. Section 348(b)(1) provides that "any person" may file a "petition proposing the issuance of [such] a regulation." Id. Section 348(d) also allows the Secretary to propose a regulation on his or her own initiative. Id. Section 348(c) lays out the Secretary's obligations in regard to a food additive petition, including a prohibition against issuing a regulation allowing use if a "fair evaluation of the data" "fails to establish that the proposed use" will be "safe." Id.

258. The FDCA "does not prescribe procedures for determining whether a food substance is GRAS." HutT \& MERRILL, supra note 23, at 408. The definition of food additives and the exclusion of GRAS substances from that definition are "self-executing;" the statute "does not require approval or even knowledge by FDA of the GRAS status of a food substance." Id.

259. The FDA's 1997 analysis of the option to eliminate all FDA responsibility in the GRAS process states:

If FDA no longer participates in independent GRAS determinations, FDA will not be aware of substances that have been the subject of independent GRAS determinations unless firms choose to submit FAP's [food additive petition] for those substances. Any public health benefits associated with FDA awareness of these substances will be lost.

Substances Generally Recognized as Safe, 62 Fed. Reg. at 18,959.

260. Ctr. for Food Safety Complaint, supra note 25, at 12.

261. See O'Reilly, supra note 6, at 424-25 (discussing the deference owed under the FDA's 1997 procedures).

262. Maranda White, FSMA Empowers FDA to Capture Food Safety's 'Great White 
Requiring producers to notify the FDA of SRAS self-determinations does not provide anything like the pre-market approval process Congress mandated in 1958. To the contrary, the proposal continues the present practice of treating additives as presumptively safe based on nothing more than producer or industry determinations of safety. But the proposal for mandatory SRAS notification would give the FDA much more information than it has now about the substances actually present in our foods. Even assuming the FDA lacks the resources to review these notifications in detail, it could make available a list of all substances for which it has received SRAS notifications. ${ }^{263}$ Consumers would then have, at least in theory, an opportunity to investigate additives of concern to them and to file citizen petitions requesting FDA review of particular substances believed to be problematic. ${ }^{264}$ In fact, consumer advocacy groups have increasingly resorted to litigation "to fill the void left by the inactive government agencies."265 Moreover, both the FDA and consumers would be able to estimate total exposure to particular substances, thus arriving at a more comprehensive evaluation of the safety of consumption either on an individual or societal level. In that process,

Whale-GRAS, FoOD SAFETY News (Apr. 10, 2015), http://www.foodsafetynews.com/2015/ 04/fsma-empowers-fda-to-capture-the-great-white-whale-of-food-safety-gras/\#.VbJ25flViko [perma.cc/4DN5-FYJN].

263. See Gen. Accounting Office, supra note 94, at 17-19 (discussing reports by the Flavor \& Extract Manufacturers Association to the FDA regarding FEMA's GRAS determinations on behalf of its member companies).

264. According to the 1997 Notice:

FDA believes that there would be considerable interest, from a broad segment of the public, including members of the regulated industry, other Federal, State, and local government agencies, international government agencies, and public interest groups, in notices received under proposed $\S 170.36$. Such groups likely would want to know whether FDA is aware that a substance is being used in food on the basis of the GRAS exemption and whether FDA has advised the notifier that it has identified a problem with the notice. Therefore, FDA is proposing to establish a procedure whereby all members of the public could readily access such information. Moreover, such a procedure would be in keeping with the agency's goals in meeting the Reinventing Food Regulations...

FDA has tentatively concluded that making both the GRAS exemption claim provided under proposed $\S 170.36(\mathrm{c})(1)$ and all letters issued by the agency relevant to each claim easily accessible to the public is the most direct and administratively efficient way of meeting the needs of the public. Accordingly, under proposed $\S 170.36(f)(2)$, the following information would be readily accessible for public review and copying: (1) A copy of all GRAS exemption claims received under proposed $\$ 170.36(\mathrm{c})(1)$; (2) a copy of all letters issued by the agency under proposed $\$ 170.36(\mathrm{e})$; and (3) a copy of any subsequent letter issued by the agency.

Substances Generally Recognized as Safe, 62 Fed. Reg. at 18,952-53.

265. Negowetti, supra note 7, at 7-8 (discussing the Center for Science in the Public Interest's litigation to address the FDA's "abdicat[ion]" of regulatory responsibility). 
it would also be possible to assess the impact of distinct substances that have similar effects in the body ${ }^{266}$ Finally, a complete inventory of substances present in food would allow producers, consumers, competitors, and regulators to monitor safety on an ongoing basis, as discussed in the next section.

\section{B. Ongoing Duty to Monitor Safety and Report to FDA}

The FDA made headlines in 2015 when it effectively banned further use of trans fats in food. ${ }^{267}$ Without acknowledging the GRAS history of these substances, a blog on the FDA's website explains this action:

FDA is taking a step today to remove artificial trans fat from the food supply. This action will save many thousands of lives.

PHOs or partially hydrogenated oils have been used as ingredients since the 1950s to improve the shelf-life of processed foods ... In this case, it has become clear that what's good for extending shelf-life is not equally good for extending human life. A 2002 report by the National Academy of Sciences' Institute of Medicine found a direct correlation between intake of trans fat and increased levels of low density lipoprotein (LDL) cholesterol ... What this means is that there is an increased risk of heart disease, so much so that this action is expected to reduce coronary heart disease and prevent thousands of fatal heart attacks each year.

In 2006, FDA required that manufacturers declare the amount of trans fat on the Nutrition Facts label because of these public health concerns. Many manufacturers responded by voluntarily changing their product formulations to reduce or eliminate trans fat, and consumers started avoiding foods with trans fat.

Despite the declines in trans fat in foods, PHOs have continued to be

266. See Substances Generally Recognized as Safe, 62 Fed. Reg. at 18,949 ("Proposed $\$ 170.36(\mathrm{c})(4)(\mathrm{i})(\mathrm{A})$ specifies that the discussion in the notice summary include a consideration of the probable consumption of the substance and the cumulative effect of the substance in the diet, taking into account any chemically or pharmacologically related substances in such diet. This consideration of dietary exposure is mandated for food additives by section 409(c)(5) of the act.").

267. See, e.g., Jen Christensen, FDA Orders Food Manufacturers to Stop Using Trans Fat Within Three Years, CNN (Jun. 16, 2015), http://www.cnn.com/2015/06/16/health/fda-trans-fat/ [perma.cc/R4W3-5646]; Brady Dennis, FDA Moves to Ban Trans Fat from U.S. Food Supply, WASH. Post (Jun. 16, 2015), https://www.washingtonpost.com/national/health-science/fda-movesto-ban-trans-fat-from-us-food-supply/2015/06/16/f8fc8f18-1084-11 e5-972649d6fa26a8c6_story.html [perma.cc/2TT7-GEKP]; Kimberly Leonard, FDA Bans Trans Fats in Move That Will Alter U.S. Food Landscape, U.S. News \& World ReP. (Jun. 16, 2015), http:/www.usnews.com/news/articles/2015/06/16/fda-bans-trans-fats-in-move-that-will-alter-usfood-landscape [perma.cc/D7G8-863L]. 
found in some brands of popular food products, such as frostings, microwave popcorn, packaged pies, frozen pizzas, stick margarines and coffee creamers. And for consumers who consistently choose products with added PHOs, their daily intake of industrially-produced trans fat is approximately twice as high as the average consumer. Today, FDA has issued its determination that PHOs are not generally recognized as safe. ${ }^{268}$

The FDA's reversal of position on trans fats and other formerly GRAS substances resulted from the agency's awareness of new scientific and medical evidence as well as new information about changing patterns of consumption of the same or similar substances in the typical American diet. There are many ways for the FDA to learn of such new evidence: reports in the popular press, statements of public health authorities such as the CDC, actions of groups such as the Institute of Medicine, which plays a key role in the periodic revision of the Dietary Guidelines for Americans, and the court and agency filings of public interest advocacy groups are all likely sources of such information. ${ }^{269}$ One scholar reports that "FDA continually reviews the safety of approved additives based on the latest scientific knowledge to determine if approvals should be modified or withdrawn." ${ }^{270}$ Given frequent laments about understaffing and underfunding of the FDA - not to mention the FDA's decision not to review for actual safety under the 1997 GRAS notification procedure - one wonders how far to trust the FDA's monitoring.

For that reason, producers should be explicitly required to monitor, on an ongoing basis, the safety of additives they use and to report new information to the FDA. ${ }^{271}$ This step is not a giant leap. The producer already has the burden of proof that an additive is excluded as GRAS. ${ }^{272}$ GRAS status is not a permanent exclusion from treatment as an additive subject to the pre-market approval scheme. ${ }^{273}$ Under existing law, it is the responsibility of producers,

to market safe ... products and to ... protect the public from adulterated products ... that have already reached the marketplace. Indeed, it is not unusual for a firm, when it learns that a distributed product is defective,

268. Mayne, supra note 50.

269. See Gen. ACCOUNTING OfFICE, supra note 6, at 21 (describing means by which the FDA learns of safety concerns related to GRAS substances).

270. FORTIN, supra note 9, at 266 (referring to substances for which a regulation has been issued pursuant to a food additive petition).

271. This Article does not suggest that the firm be required to make a more public announcement of potentially adverse information. The FDA, likely in consultation with the firm(s) involved, would presumably decide when mounting evidence of a safety issue requires broader dissemination of the information. This is similar to the existing method for voluntary recalls, under which producers are encouraged to report problems to the FDA; the agency may then request a recall. See HutT \& MERRILL, supra note 23, at 1307-08 (discussing recall strategy).

272. United States v. An Article of Food, 752 F.2d 11 (1st Cir. 1985).

273. ForTIN, supra note 9, at 266; HutT \& MERRILL, supra note 23, at 414. 
to take steps to correct the situation by removing the product from commerce or by remedying the defect. ${ }^{274}$

FDA policy calls for firms to "promptly notify FDA when products are being removed or corrected." 275

According to the Supreme Court:

[The FDCA] imposes not only a positive duty to seek out and remedy violations when they occur but also, and primarily, a duty to implement measures that will insure that violations will not occur. The requirements of foresight and vigilance imposed on responsible corporate agents are beyond question demanding, and perhaps onerous, but they are no more stringent than the public has a right to expect of those who voluntarily assume positions of authority in business enterprises whose services and products affect the health and well-being of the public that supports them. ${ }^{276}$

Furthermore, the FSMA, the most recent food safety statute, requires producers to identify and evaluate hazards including "unapproved food additives" in their written food safety plans, to make documentation of this evaluation available upon request to the FDA, and to reevaluate such hazards at least once every three years. ${ }^{277}$ Thus, the legal framework already places significant responsibility upon producers to monitor the safety of their products on an ongoing basis.

The proposed duty of producers to notify the FDA of new information about the safety of their products is a modest extension of these existing duties. Producers, understandably, are loath to reveal adverse information about their products, especially when the evidence remains contested. Nonetheless, it can be expected that most firms would comply with a mandatory notification requirement. ${ }^{278}$ To be meaningful, the obligation on producers would extend to

274. Enforcement Policy, Practices and Procedures: Recall Policy and Procedures, 41 Fed. Reg. 26,924, 26,924 (Jun. 30, 1976) (to be codified at 21 C.F.R. pt. 2) (discussing voluntary recalls on a firm's own initiative or upon FDA request). The Food Safety Modernization Act provided the FDA with mandatory recall authority in certain circumstances. Draft Guidance for Industry: Questions and Answers Regarding Mandatory Food Recalls, FoOD \& DRUG Admin., http:/www.fda.gov/Food/GuidanceRegulation/GuidanceDocumentsRegulatoryInformation/ucm 445428.htm [perma.cc/A4ZN-6QVK] (last updated July 30, 2015).

275. Enforcement Policy, Practices and Procedures: Recall Policy and Procedures, 41 Fed. Reg. at 26,928 .

276. United States v. Park, 421 U.S. 658, 672 (1975). Recent enactments, notably the FSMA, go even further in imposing duties on producers under the Hazard Analysis and Critical Control Point (HACCP) model to monitor and document operations continuously for safety. See ForTIN, supra note 9, at 241. Though not yet applicable to all parts of the food industry, HACCP is "widely recognized as the best approach for improving food safety." Id.

277. John S. White, Straight Talk About High-Fructose Corn Syrup: What It Is and What It Ain't, 88 AM. J. CliniCAL Nutrition 1716S, 1716S-21S (2008).

278. Cf. HutT \& MERRILL, supra note 23, at 1303 (discussing fact that manufacturers "almost 
reporting new information that raises credible questions about safety, even when the evidence overall is mixed and no recall or other corrective action is clearly warranted. ${ }^{279}$ The obligation to report at this stage would allow the producer, the FDA, and consumers to monitor the situation more closely.

To take one example of the importance of monitoring and reporting on safety, consider the current debate about HFCS. The FDA affirmed HFCS as GRAS in 1983. But this action was taken "way before the sugar glut" hit American diets, ${ }^{280}$ "based on . . . average sugar consumption of 40 pounds per person per year." ${ }^{281}$ Consumption has exploded: "We're now at 130 pounds per person per year." 282 Moreover, medical science did not recognize until recently that although "fructose does not specifically cause obesity[,] it turns obesity into metabolic syndrome." 283 Meanwhile, the corn refining industry, which produces HFCS, embarked on an advertising campaign to convince consumers that HFCS was as safe as sugar. ${ }^{284}$ These claims are hotly contested and are one battlefield in the competitive war between the corn refiners and the sugar industry. ${ }^{285}$ Changing patterns of consumption of various sweeteners, along with new medical evidence about their health effects, suggest that HFCS is less safe - taking into account all the statutory factors - than it appeared to be several decades ago.

This highly publicized saga reflects the high stakes both producers and consumers attach to the regulatory status of food. It would seem to be a textbook case for mandatory ongoing monitoring of evidence relating to safety. The requirement to monitor safety and report to the FDA comports with the HACCP approach that increasingly dominates the United States' food safety regime. Requiring producers to monitor safety and report to the FDA, standing alone,

always comply with FDA recall requests").

279. One way to approach drafting such a provision might be to use the "evidence-based ranking system for scientific data" proposed for health claims as a model. See FOOD \& DRUG Admin., Guidance for Industry: Interim Evidence-based RANKIng System For SCIENTIFIC DATA (2003), available at http://www.fda.gov/ohrms/dockets/dailys/03/Aug03/080103/03n-0069rpt0001-04-Attachment-b-vol4.pdf[http://perma.cc/G8BZ-WNJ2] (linking the strength of scientific evidence and degree of consensus to regulatory treatment of proposed claims that particular foods would help prevent particular diseases).

280. Lustig, supra note 148, at 242.

281. Id.

282. Id.

283. Id. Lustig noted that "[y]ou don't die of obesity; you die of the diseases that 'travel' with it ... [such as] "diabetes, hypertension, heart disease, [and] cancer . . . [which are] collectively packaged under the concept of 'metabolic syndrome." Id. at 94.

284. See Eric Lipton, Rival Industries Sweet-Talk the Public, N.Y. Times, Feb. 12, 2014, at B1, available at http://www.nytimes.com/2014/02/12/business/rival-industries-sweet-talk-thepublic.html?_r=0 [http://perma.cc/5GD7-DDT7]. The refiners also attempted to convince the FDA that "corn sugar" would be an appropriate name for HFCS and that HFCS is "natural." Id. The FDA denied both requests. See Choi, supra note 173.

285. Lipton, supra note 284. 
would disappoint petitioners seeking an immediate ban on use of a particular additive, for example. But it would provide a foundation for regulatory response to developing safety concerns.

\section{The FDA's Authority to Revise or Revoke GRAS Status}

The history of food additive regulation reinforces what is already obvious: the food supply changes constantly and scientific knowledge evolves. Regardless of how the FDA learns of new information calling into question the safety of a substance already in the food supply, the FDA may revise the permitted conditions of use under a food additive regulation or revoke GRAS status entirely. Thus, requiring producers to monitor safety and report adverse information to the FDA is not a meaningless exercise. The GAO takes the FDA to task for its own failure to "systematically reconsider[] the safety of substances considered to be GRAS as new scientific information has come to light" ${ }^{286}$ and for its lack of awareness of whether or to what extent food producers "track the evolving scientific information regarding substances [they] have determined are GRAS."287

Although it lacks an explicit authorization to revoke GRAS status, ${ }^{288}$ the 1958 Act clearly contemplates review in light of new information. Section 348(a)(2) deems food additives unsafe unless "there is in effect ... a regulation ... prescribing the conditions under which such additive may be safely used" and the use conforms with that regulation. ${ }^{289}$ Even under existing law, the GRAS exception is limited. It applies to a particular use, not to the substance itself; new uses of a substance that is GRAS for some other use are not automatically GRAS. ${ }^{290}$ A leading authority explained that "[a]n ingredient's status as GRAS is always vulnerable to the discovery of new evidence casting doubt on its safety." 291 "An ingredient that ceases to be GRAS falls automatically within the definition of a food additive, and must then be approved by the FDA for its use to be lawful." 292 In addition, section 348(i) currently provides that "[t]he Secretary shall by regulation prescribe the procedure by which regulations under the foregoing provisions of this section may be amended or repealed." ${ }^{293}$ This

286. Gen. AcCounting OfFice, supra note 6, at 21.

287. Id. at 25 .

288. This authority is implicit. See 21 U.S.C. §348(i) (2012) (authorizing the Secretary to promulgate procedures for the amendment or repeal of regulations pursuant to $\S 348)$; id. $\$ 321(\mathrm{~s})$ (conferring GRAS exemption on an additive "if such substance is [] generally recognized as safe ...") (emphasis added).

289. Id. § 348(a)(2).

290. See, e.g., United States v. An Article of Food, 752 F.2d 11, 16 (1st Cir. 1985) (holding the use of potassium nitrate in soft drinks as not GRAS despite the fact that nitrates are naturally present in many foodstuffs and that they have been used for centuries to cure meats).

291. HutT \& MERRILL, supra note 23, at 414.

292. $I d$.

293. 21 U.S.C. $§ 348(i)$. 
provision apparently refers to food additive regulations, but if substances whose use is permitted only by regulation after rigorous review are vulnerable to new evidence casting doubt on safety, it would seem that substances the FDA has never affirmed as safe should be equally vulnerable. Thus, GRAS determinations, however made, are already subject to revocation on the basis of new information relating to safety. This includes new information that the concentration of a particular additive in the food supply, and hence in the typical diet, has reached the stage where cumulative exposure over a lifetime can no longer be considered safe. ${ }^{294}$

The FDA's actions under existing law reinforce this understanding. Two examples, separated by decades, are illustrative. The FDA states that in 1969, it "removed various cyclamate salts, a family of nonnutritive sweeteners, from the GRAS list because they were implicated in the formation of bladder tumors in rats. ${ }^{295}$ Responding to a presidential directive in reaction to this incident, the FDA subsequently announced that the agency "was conducting a "comprehensive review' of presumed GRAS substances" to re-assess safety information about these substances." ${ }^{296}$ Similarly, the FDA announced in 2015:

Based on a thorough review of the scientific evidence, the [agency] [had] finalized its determination that partially hydrogenated oils (PHOs), the primary dietary source of artificial trans fat in processed foods, are not "generally recognized as safe" (GRAS) for use in food. This action is expected to reduce coronary heart disease and to prevent thousands of fatal heart attacks each year. ${ }^{297}$

In both cases, the FDA acted on the basis of new scientific evidence that cast

294. See id. $\S 348(c)(5)$ (requiring the FDA to consider safety factors including "probable consumption ... [and] cumulative effect . . . in the diet . . taking into account any chemically or pharmacologically related substance ... in [the] diet"). For an example, see Lustig's discussion of HFCS in the context of increased consumption of sugars. LUSTIG, supra note 148, at 242.

295. Substances Generally Recognized as Safe, 62 Fed. Reg. 18,938, 18,939 (Apr. 17, 1997) (to be codified at 21 C.F.R. pt. 170) (citing Cyclamic Acid and its Salts, 34 Fed. Reg. 17,063 (Oct. 21,1969 ) (to be codified at 21 C.F.R. pt. 121)) (noting that in response to the concerns raised by the new information on cyclamates, President Nixon directed the FDA to reexamine the safety of GRAS substances); see also id. (citing Food Additives, 35 Fed. Reg. 18,623 (Dec. 8, 1970) (to be codified at 21 C.F.R. pt. 121)). As potential carcinogens, cyclamates fell under the particularly strict provisions of the so-called Delaney Clause, which prohibits the Secretary from issuing a food additive regulation in the face of evidence that it may cause cancer. 21 U.S.C. § 348(c)(3)(A). The President's action apparently reflected a broader concern with the safety of food additives.

296. FDA's Approach to the GRAS Provision: A History of Processes, Food \& DRUG. AdmIN., http://www.fda.gov/Food/IngredientsPackagingLabeling/GRAS/ucm094040.htm [http://perma.cc/SJ4K-M4BU] (last updated July 25, 2015).

297. FDA Takes Step to Remove Artificial Trans Fats from Processed Foods, FoOD \& DRUG. Admin. (June 16, 2015), http://www.fda.gov/Food/NewsEvents/ConstituentUpdates/ucm449145. htm [http://perma.cc/PPC8-2V5G]. 
doubt on previous determinations of the safety of a substance added to food. ${ }^{298}$

This is not to say that the FDA is required to take a particular action at a particular time. In some cases, as with trans fats, the FDA chooses to move incrementally, imposing additional requirements as the scientific evidence about safety develop. ${ }^{299}$ A petition to ban use of these substances altogether had been before the FDA since at least $2004 .^{300}$ The 2015 revocation of GRAS status for trans fats was preceded in 2003 by a labeling requirement to inform consumers of the presence of trans fats in food products. ${ }^{301}$ When evidence of ill effects of consumption of trans fats mounted, the FDA concluded that labeling was no longer an adequate response. Only then did the FDA revoke GRAS status of trans fats, effectively banning their further use in food. ${ }^{302}$ The FDA's delay in revoking GRAS status for trans fats was not based on lack of authority to act.

\section{Summary}

This Article proposes new obligations on producers of foods containing additives. The current voluntary notification procedure would be made mandatory. Producers would also be required to monitor safety of such substances on an ongoing basis and to report credible evidence raising questions about safety to the FDA. These requirements all comport with existing regulatory authority. The FDA's existing authority to revise or revoke approval of substances would remain in place and could be invoked more effectively on the basis of the proposed notification, monitoring, and reporting requirements.

298. Another example of changing evidence of safety is found in the 2015 petition by a number of public interest groups asking the FDA to ban the use of eight synthetic flavorings on the basis of determinations by the National Toxicology Program pursuant to congressional mandate that the substances are either "reasonably anticipated to be a human carcinogen" (two flavorings) or "possibly carcinogenic to humans" (six flavorings). Petition from Ctr. for Sci. in the Pub. Interest et al. to Dennis Keefe, Dir. of the Office of Food Additive Safety, Ctr. for Food Safety \& Applied Nutrition (June 10, 2015), available at http://docs.nrdc.org/health/ files/hea_15060901a.pdf [http://perma.cc/F46Q-3U4Z]. All eight flavorings had previously been found to be safe, seven by the FDA's issuance of a regulation in 1964 and the eighth by the Flavor and Extract Manufacturers Association's own GRAS determination in 1974. See Petition Asks FDA to Ban 8 Synthetic Flavorings Now Considered GRAS, supra note235. These substances "were allowed on the market long before animal studies showed that the chemicals cause cancer." Id.

299. Food Labeling: Trans Fatty Acids in Nutrition Labeling, Nutrient Content Claims, and Health Claims, 68 Fed. Reg. 41,434, 41,436 (July 11, 2003) (to be codified at 21 C.F.R. pt. 101).

300. Final Determination Regarding Partially Hydrogenated Oils, 80 Fed. Reg. 34,650-01, 34,667 (June 17, 2015) (discussing the Center for Science in the Public Interest's citizen petition).

301. Id at 41,450 . The FDA first published a proposed rule on labeling in 1999. Food Labeling: Trans Fatty Acids in Nutrition Labeling, Nutrient Content Claims, and Health Claims, 64 Fed. Reg. 62,746 (Nov. 17, 1999) (to be codified at 21 C.F.R. pt. 101). The Final Rule promulgated in 2003 took effect in 2006.

302. The FDA established a compliance date of June 18, 2018. Final Determination Regarding Partially Hydrogenated Oils, 80 Fed. Reg. at 34,651. 


\section{Labeling Products Containing Artificial and Synthetic SUbSTANCES AS "NATURAL" "303}

Many products containing artificial and synthetic additives are currently labeled as "natural." "304 This tactic, which deceives consumers, violates the FDCA's prohibition on sale in interstate commerce of food that is misbranded by way of misleading representations in its labeling. This Article suggests that "food additives" be distinguished from "food" on the basis of additives' derivation from non-naturally occurring sources or their synthesis in laboratories. That proposal immediately implies that products containing additives are not natural. If that is so, labeling such products as "natural" is misleading and their sale is unlawful as misbranded.

Consumers, public interest organizations, and food producers have long petitioned the FDA to define the term "natural" in the context of food labeling. ${ }^{305}$ The agency has considered the matter, going so far as to issue proposed regulations in $1991,{ }^{306}$ but ultimately chose not to proceed with the rulemaking. ${ }^{307}$ The FDA's denial cited the relative lack of priority devoted to this issue ${ }^{308}$ as well as its belief that the multitude of varying claims already in use makes regulation impossible. ${ }^{309}$ It seemed pointless to continue challenging that

303. For simplicity, this Article uses the term "natural" to encompass related claims such as "all natural," "made with natural flavors," etc.

304. See, e.g., Food Labeled 'Natural' May Not Be, Consumer Advocates Warn, supra note 11; see also Sarah L. Brew, FDA Takes a Step Forward on "Natural" Food Labeling, L. 360 (Nov. 25, 2015), http://www.law360.com/articles/731406/print?section+consumerprotection [perma.cc/Y59C-RRWM] (describing the interests of consumer and industry groups).

305. April L. Farris, The "Natural" Aversion: The FDA's Reluctance to Define a Leading Food-Industry Claim, and the Pressing Need for a Workable Rule, 65 FoOD \& DRUG L.J. 403, 40607 (2010) (describing petitions of the Sugar Association and food producer Sara Lee Corporation).

306. Food Labeling: Nutrient Content Claims, General Principles, Petitions, Definition of Terms, 56 Fed. Reg. 60,421, 60,466-67 (proposed Nov. 27, 1991). Even earlier, the Federal Trade Commission, which oversees food advertising, attempted to regulate "natural" claims, but later abandoned the effort. See Laura Lorenzetti, The Government May Finally Define "Natural " Food, ForTUNE (Nov. 11, 2015, 12:25 PM), http://fortune.com/2015/11/11/fda-natural-food-label [perma.cc/V4S9-JJWF].

307. See Farris, supra note 305, at 404-08 (reporting conclusions of the FDA); see also id. at 408-11 (reporting conclusions of the USDA).

308. Id. at 407.

309. As the FDA noted in 1991:

One possible meaning of the term "natural" as it applies to food is the absence of artificial or synthetic ingredients of any kind. This meaning, however, has been degraded by inappropriate use of the term in the marketplace . . . Because of the multiple and diverse meanings currently in use, establishing a definition for the term "natural" that will be readily accepted and understood will be difficult.

Food Labeling: Nutrient Content Claims, General Principles, Petitions, Definition of Terms, 56 
decision, to which the federal courts would probably have decided deference is due. ${ }^{310}$ But in a surprise move, the FDA announced in October 2015 that it was once again seeking public comment on the "natural" labeling issue. ${ }^{311}$ This announcement indicates that the FDA is aware that the "natural" label is often misleading. In addition, state and federal legislative developments may have increased pressure on the FDA to revisit this issue. ${ }^{312}$ Notably, the U.S. House of Representatives in July 2015 passed the Safe and Accurate Food Labeling Act, ${ }^{313}$ which would require the FDA to regulate use of the term "natural" on food labels. ${ }^{314}$ Under that bill, a food whose "labeling contains an express or implied claim that the food is "natural" is misbranded unless the "claim uses terms that have been defined by, and the food meets the requirements [of] regulations ... promulgated to carry out this paragraph." 315

It is too soon to tell whether the FDA will overcome its previous reservations this time around, or whether it will try a different approach. ${ }^{316}$ Whatever the FDA decides to do, "the process will involve many steps over many years." 317 This

Fed. Reg. at 60,466-67.

310. The statute confides discretion to the Secretary both in determining which information should (or should not) appear on labels and whether or when to promulgate such regulations. 21 U.S.C. § 371(a) (2012). It provides general authorization to "promulgate regulations for the efficient enforcement of [the FDCA]." Id. Under Chevron v. Nat'l Res. Def. Council, 467 U.S. 867, 883-84 (1984), "If Congress has explicitly left a gap for the agency to fill, there is an express delegation of authority to the agency to elucidate [it] by regulation. Such legislative regulations are given controlling weight unless they are arbitrary, capricious, or manifestly contrary to the statute."

311. See, e.g., FDA Requests Comments on Use of the Term "Natural" on Food Labeling, Food \& Drug Admin. (Nov. 10, 2015), http://www.fda.gov/Food/NewsEvents/Constituent Updates/ucm471919.htm [http://perma.cc/6XBJ-RTZB] (noting that the FDA is accepting public comments until May 10, 2016 on defining the term "natural").

312. Brew, supra note 304 (discussing state GMO labeling proposals and federal Safe and Accurate Food Labeling bill).

313. H.R. 1599, 114th Cong. (2015). The bill is better known for its provisions relating to genetically engineered plants and foods. The bill was sent to the Senate, where an attempt was made to incorporate its provisions into an end-of-year budget measure; that attempt was rejected on Dec., 16. 2015. See Shannon Van Hoesen, EWG Applauds Exclusion of Anti-GMO Labeling Rider in Omnibus, ENVTL. WORKING GRP. (Dec. 16, 2015), http://www.ewg.org/release/congress-rejectsrider-block-gmo-labeling [perma.cc/TP4E-MHY6] (stating that an "end-of-the-year, must-pass spending bill is the wrong vehicle to address an issue as important as our right to know what's in our food").

314. H.R. 1599 at 35 (Title III, $\S 301$ of Act, amending 21 U.S.C. $\S 403$ ); see also Brew, supra note 304 (stating that bill sends a "clear message" that "if FDA won't act on 'natural,' other government entities will").

315. H.R. 1599 at 35.

316. See Brew, supra note 304 (warning the food industry not to expect the FDA to issue a rule "any time soon" and noting that the 2015 action is not "even an advance notice of proposed rulemaking").

317. Id. 
Article argues that a narrower approach than those considered in the past might succeed this time. Rather than attempting to define the term "natural" for all uses, the FDA should simply prohibit use of the term with respect to certain products, notably those containing food additives, and perhaps in certain locations, such as on the front of packages.

\section{A. Foods Containing Artificial Additives are not "Natural"}

Though the line dividing natural from non-natural products is not perfectly clear, it can be applied fairly readily using common sense. Recall the example of HFCS. ${ }^{318}$ As its name implies, this substance is derived from corn, ${ }^{319}$ but the description of the process required to manufacture $\mathrm{it}^{320}$ makes clear that HFCS bears no resemblance to what consumers regard as "corn." Nor is HFCS the same as ordinary sugar, or for that matter, as corn syrup. ${ }^{321}$ Whatever its effect on the body, ${ }^{322}$ HFCS is a distinct substance-and regulation of food additives begins with the identification of novel "substances." 323 HFCS, a product not even available to home cooks, surely qualifies. ${ }^{324}$ It is used "principally as a replacement for sucrose [table sugar]" because "its sweetness [is] comparable with that of sucrose," but it offers "improved stability and functionality, and ease

318. See supra text accompanying notes 171-72.

319. See Elea Carey, High Fructose Corn Syrup vs. Sugar: What's the Difference?, HEALTHLine (Sept. 22, 2014), http://www.healthline.com/health/high-fructose-corn-syrup-or-sugar [http"//perma.cc/W8YF-FQYC] ("Both sugar and HFCS begin out in the field: sugar as sugarcane [or sugar beets], and HFCS as corn.").

320. The FDA's "understanding" of the process is that "the enzyme used to make HFCS is fixed to a column by use of the synthetic fixing agent, glutaraldehyde. Any unreacted glutaraldehyde is removed by washing the column prior to the addition of high dextrose equivalent corn starch hydrolysate, which undergoes enzymatic reaction to produce HFCS." Letter from Geraldine June, Ctr. for Food Safety \& Applied Nutrition to Audrae Erickson, Corn Refiners Ass'n (July 3, 2008), available at http://www.corn.org/wp-content/uploads/2008/07/ FDAdecision7-708.pdf [http://perma.cc/42AL-VW8N] (stating that the FDA would not object to labeling of products containing HFCS as natural if HFCS were manufactured in such a way that the fixing agent never came into contact with the corn starch hydrolysate).

321. See Carey, supra note 319 ("[T] make HFCS, caustic soda is used to 'shuck' the corn kernel from its starch. (The result is the corn syrup you might have used to make pecan pie.) Then enzymes are introduced to convert the syrup's sugars to super-sweet fructose. Unlike sugar [or corn syrup], you'll never see HFCS on the supermarket shelves. It's only available to food processors.").

322. The effect of HFCS as opposed to ordinary sugar in causing diabetes, obesity, and other conditions is hotly contested. Compare, LUSTIG, supra note 148, at 19-21, with White, supra note 277 , at $1716 \mathrm{~S}$.

323. 21 U.S.C. § 321(s) (2012); see also supra Part III.

324. See Hope Warshaw, High-fructose Corn Syrup vs. Sugar, WASH. Post (June 18, 2013), http://www.washingtonpost.com/lifestyle/wellness/high-fructose-corn-syrup-vssugar/2013/06/18/fdbedb90-c488-11e2-914f-a7aba60512a7_story.html [http://perma.cc/4KZXKYS2] ("High-fructose corn syrup . . . can be bought only by food manufacturers."). 
of use" for food producers. ${ }^{325}$ It also is cheaper than sugar. ${ }^{326}$ In other words, it is used precisely to replace a naturally-occurring, traditional food ingredient that does not suit the needs of producers of processed foods. HFCS does not meet any ordinary definition of the term "natural." It is an additive used intentionally to achieve functional effects in food products. Even so, supermarket shelves are overflowing with processed foods containing HFCS and many other additives but labeled "natural." 327

Several aspects of the FDA's own policy support this Article's distinction of additives from traditional food ingredients on the basis that additives are nonnaturally occurring substances ${ }^{328}$ as well as the argument that the term "natural" is misleading as applied to these substances or to products containing them. In describing its decision not to define the term "natural," the FDA recently reiterated:

From a food science perspective, it is difficult to define a food product that is 'natural' because the food has probably been processed and is no longer the product of the earth. That said, FDA has not developed a definition for use of the term natural or its derivatives. However, the agency has not objected to the use of the term if the food does not contain added color, artificial flavors, or synthetic substances. ${ }^{329}$

This statement implies that processed foods, unlike whole foods, generally are not "natural" products. The FDA's enforcement policy-tacitly accepting use of the term "natural" only on products that do not contain added colors, artificial flavors, or synthetic substances - reflects an emphasis on the use of additives in determining what is natural. The FDA elaborated that it "regard[s] the use of 'natural' as meaning that nothing artificial or synthetic ... has been included in, or has been added to, a food that would not normally be expected to be in the food." ${ }^{330}$ The use of words like "added," "artificial," and "synthetic" is important.

325. White, supra note 277 , at 1716 S (comparing HFCS to ordinary sugar ("sucrose")).

326. See Shereen Lehman, Food Fight-Regular Sugar Versus High Fructose Corn Syrup, Aвоut HeALth (Dec. 10, 2014), http://nutrition.about.com/od/grainsandcereals/f/fructosesyrup. htm [http://perma.cc/WS7N-8ZVN] ("High fructose corn syrup is cheaper than regular sugar so it's [sic] use as an ingredient in processed foods and beverages has increased over the past few decades.").

327. Processed foods may also be labeled using terms like "healthy," "good for you," and numerous others. The regulation of claims suggesting health benefits is beyond the scope of this Article.

328. See supra Part II.C.

329. What Is the Meaning of the Term 'Natural' on the Label of Food?, FoOD \& DRUG ADMIN., www.fda.gov/AboutFDA/Transparency/Basics/ucm214868.htm [http://perma.cc/JZY7CPGD] (last updated Nov. 10, 2015). The FDA originally articulated this policy 1991. Food Labeling: Nutrient Content Claims, General Principles, Petitions, Definition of Terms, 56 Fed. Reg. 60,421, 60,466-67 (proposed Nov. 27, 1991)

330. Food Labeling: Nutrient Content Claims, General Principals, Petitions, Definition of Terms; Definitions of Nutrient Content Claims for Fat, Fatty Acid, and Cholesterol Content of 
These statements bespeak a common-sense understanding that products formulated using novel substances unknown as traditional food ingredients and unavailable to home cooks are not "natural" foods.

By way of illustration, consider examples of FDA warning letters. Such letters have declared products to be misbranded where the label included the representation "all natural," but the product contained a single "synthetic chemical preservative" 331 or contained a synthetic substance." 332 The FDA notes specifically that it "considers use of the term 'natural' on a food label to be truthful and non-misleading" when the product contains "nothing artificial or synthetic." "333 This statement makes clear that the FDA recognizes its broad authority to address misbranding of foods whose labels make "misleading claims," even when the label elsewhere truthfully reveals the inclusion of a chemical or synthetic substance.

\section{B. Ingredient Listing is Inadequate to Counter Front-of-Package Claims}

Likewise, the FDA's focus on what consumers "expect" to be in their foods reflects a concern for potential deception, particularly in light of the fact that front-of-package claims capture consumers' attention and often drive purchasing decisions ${ }^{334}$ In fact, the FDCA provides robust authority to address misleading claims on food labels. Section 321(n) provides in full:

If an article is alleged to be misbranded because the labeling or advertising is misleading, then in determining whether the labeling or advertising is misleading there shall be taken into account (among other things) not only representations made or suggested by statement, word, design, device, or any combination thereof, but also the extent to which the labeling or advertising fails to reveal facts material in the light of such representations or material with respect to consequences which may result from the use of the article to which the labeling or advertising relates under the conditions of use prescribed in the labeling or advertising thereof or under such conditions of use as are customary or usual. ${ }^{335}$

Food, 58 Fed. Reg. 2302, 2407 (Jan. 6, 1993) (to be codified at 21 C.F.R. pt. 101).

331. Alexia Foods, Inc. 11/16/11, Food \& DRUG AdmIN. (Nov. 16, 2011), http://www. fda.gov/ICECI/EnforcementActions/WarningLetters/ucm281118.htm [http://perma.cc/BSF38Q3Y].

332. Middle East Bakery, Inc. 9/18/14, Food \& DrUG ADMIN. (Sept. 18, 2014), http://www.fda.gov/ICECI/EnforcementActions/WarningLetters/2014/ucm4 15564.htm [http://perma.cc/5AHB-VM3U].

333. Id. (emphasis added).

334. See Food Labeling: Nutrient Content Claims, General Principals, Petitions, Definition of Terms; Definitions of Nutrient Content Claims for Fat, Fatty Acid, and Cholesterol Content of Food, 58 Fed. Reg. at 2407.

335. 21 U.S.C. $§ 321(n)(2012)$. 
The test for misleading claims is their impact on the "reasonable" consumer, ${ }^{336}$ who cannot be expected to pick up each product, turn it around, and examine the fine print of the ingredient list and nutrition facts panel to determine whether this detailed information comports with the powerful front-of-package representation that the product is "natural."

The Supreme Court, in a 1943 case involving "enriched" farina, noted "evidence of the desire of consumers to purchase vitamin-enriched foods, their general ignorance of the composition and value of the vitamin content of those foods, and their consequent inability to guard against the purchase of products of inferior or unsuitable vitamin content." ${ }^{337}$ Though packaged food labels in 1943 provided less information than do labels today for evaluating manufacturers' claims, the analogy to modern consumers is strong.

Consumers today are strongly motivated to purchase "natural" foods on the ground that they are likely to be healthier. ${ }^{338}$ Use of this term makes products more appealing to consumers and raises profits for producers. ${ }^{339}$ Consumers have

336. See Food \& Drug. Admin., Guidance for Industry: Presenting Risk Information In Drug and Medical Device Promotion 5 (May 2009), available at http://www.fda.gov/ downloads/drugs/guidancecomplianceregulatoryinformation/guidances/ucm155480.pdf [perma.cc/R3MD-ZQTF] (reiterating the agency's view that "the reasonable consumer standard is the appropriate standard to use in determining whether a claim in the labeling of a . . . conventional food is misleading").

337. Fed. Sec. Adm'r v. Quaker Oats Co., 318 U.S. 218, 229 (1943) (upholding the standard of identity prohibiting addition of Vitamin D to "farina," but permitting its addition to "enriched farina").

338. See, e.g., Nancy Gagliardi, Consumers Want Healthy Foods and Will Pay More for Them, FORBES (Feb. 18, 2015), http://www.forbes.com/sites/nancygagliardi/2015/02/18/ consumers-wanthealthy-foods-and-will-pay-more-for-them/ [http://perma.cc/5YGT-JBXJ] (linking "healthy" foods to "natural" food production).

339. The USDA acknowledged in the preamble to its 2009 Voluntary Standard:

A number of livestock producers make claims associated with production practices in order to distinguish their products in the marketplace and there are a growing number of entities that are capturing value-added opportunities by using alternative production methods to meet the demands of consumers and markets seeking meat and meat products from naturally raised livestock.

United States Standards for Livestock and Meat Marketing Claims, Naturally Raised Claim for Livestock and the Meat and Meat Products Derived From Such Livestock, 74 Fed. Reg. 3541, 3541

(Jan. 21, 2009). In its press release announcing the new standard, the USDA stated:

The segment of the marketplace that includes specific animal raising claims has experienced exponential growth in the past five years. Use of a naturally raised marketing claim standard has the potential to increase the available supply of U.S. meat products eligible for niche marketing programs in the United States, the European Union, and other export markets that require livestock to be raised without the administration of growth promotants.

Press Release, Dep't of Agric., USDA Establishes Naturally Raised Marketing Claim Standard (Jan. 
little ability to keep up with rapidly changing medical evidence about the health effects of various foods. Accordingly, the potential for deception is clear.

Because current law mandates the listing of all "ingredients," ${ }^{340}$ except certain spices, flavorings, and colors, ${ }^{341}$ additives like HFCS are listed on product labels. Some have suggested that this listing provides consumers with all the information necessary to determine for themselves whether the product is "natural." ${ }^{342}$ But the use of terms like "natural" on the front of the package overshadows the ingredient listing in small print on the back or side of the package. For example, a study of the food-buying habits of parents of young children found:

[T] he overwhelming consensus of parents was that FOP [Front of Package] health claims would attract their attention more than anything else... Overwhelmingly, when participants were asked what parts of the packaging drew his or her attention they made statements such as:

"It looks like this is one of the 95 percent fruit juice and real fruit."

"The word natural stands out for me."

The word "natural" was lumped into being perceived as a health claim and these products were typically discussed as being more "real." In one focus group the moderator explicitly asked, summarizing previous responses to the mock-ups, "do you all think the $100 \%$ natural looks the most healthy of all the ones there?" The participants all responded, "yes."...

A few participants also noted they often read nutrition facts panels and ingredient lists on the back of packaging. ${ }^{343}$

16, 2009), available at https://www.legistorm.com/stormfeed/view_rss/438731/organization/ 95234.html [http://perma.cc/BQK8-L5UF].

340. 21 U.S.C. $\S 343(i)(2) ; 21$ C.F.R. § 101.4 (2015) (using the term "ingredients" differently from the meaning proposed in this Article). FDA regulations exclude "incidental additives" and "processing aids" from this requirement on the ground that they do not remain in the food in significant amounts and therefore are not "ingredients." Id. § 101.100.

341. Per 21 U.S.C. $§ 343(i)$, these ingredients "may be designated as spices, flavorings, and colorings without naming each."

342. See Farris, supra note 305, at 421-24 (describing list-based approaches to allow consumers to discern whether or not a food is "natural"); $c f$. Pollan, supra note 150, at 150-54 (suggesting that consumers identify "traditional" foods using a variety of rules including "[a]void food products containing ingredients that are a) unfamiliar, b) unpronounceable, c) more than five in number, or that include d) High Fructose Corn Syrup").

343. Katie M. Abrams et al., Ignorance is Bliss: How Parents of Preschool Children Make Sense of Front-of-package Visuals and Claims on Food, 87 Appetite 20-29 (Apr. 1, 2015) (internal citations omitted) (reporting results of focus group study). 
The Supreme Court implicitly recognized the importance-and the propensity to mislead - of front-of-package labeling when it described a bottle of juice this way:

Despite the minuscule amount of pomegranate and blueberry juices in the blend, the front label of the [] product displays the words "pomegranate blueberry" in all capital letters, on two separate lines ... The product's front label also displays a vignette of blueberries, grapes, and raspberries in front of a halved pomegranate and a halved apple. ${ }^{344}$

The Court concluded that a competitor's claim under the Lanham Act for unfair competition based on deceptive labeling was cognizable even with respect to a product otherwise regulated under the FDCA. $^{345}$ In so doing, the Court recognized gaps in the FDA's oversight of food and beverages that leave consumers unprotected. The Court noted:

Because the FDA acknowledges that it does not necessarily pursue enforcement measures regarding all objectionable labels, if Lanham Act claims were to be precluded then commercial interests - and indirectly the public at large - could be left with less effective protection in the food and beverage labeling realm than in many other, less regulated industries. It is unlikely that Congress intended the FDCA's protection of health and safety to result in less policing of misleading food and beverage labels than in competitive markets for other products. ${ }^{346}$

\section{The FDA Can Find a Way to Regulate "Natural" Claims}

Along the lines suggested in this Article, the FDA noted in 1991: "One possible meaning of the term 'natural' as it applies to food is the absence of artificial or synthetic ingredients of any kind." ${ }^{347}$ At that time the FDA

344. See POM Wonderful LLC v. Coca-Cola Co., 134 S. Ct. 2228, 2235 (2014) (noting that the front label also contained "the phrase 'flavored blend of 5 juices' in much smaller type" and "below that phrase, in still smaller type, were the words 'from concentrate with added ingredients' and ... 'and other natural flavors"').

345. Id . at 2238-39. According to a news story, "POM sued Coca-Cola, claiming that it was losing sales because Coca-Cola's label and advertising were misleading consumers into believing they were getting a juice combination consisting mainly of pomegranate and blueberry juices when, in fact, the juice was more than 99 percent apple and grape juices. "Nina Totenberg, POM Wonderful Wins A Round In Food Fight With Coca-Cola, NPR (Sept. 23, 2014, 7:01 AM), http:/www.npr.org/sections/thesalt/2014/06/12/321390014/pom-wonderful-wins-a-round-in-foodfight-with-coca-cola [http://perma.cc/776Y-L7KE]. POM claimed unfair competition because the "Coca-Cola product is almost five times cheaper. Only if you read down to the small print on the label do you see why: While POM's juice is 85 percent pomegranate and 15 percent blueberry juice, the Coca-Cola product is just 0.5 percent pomegranate and blueberry juice - combined." Id.

346. POM Wonderful LLC, $134 \mathrm{~S}$. Ct. at 2239.

347. Food Labeling: Nutrient Content Claims, General Principles, Petitions, Definition of 
concluded, however, that this meaning "has been degraded by inappropriate use of the term in the marketplace ... Because of the multiple and diverse meanings currently in use, establishing a definition for the term "natural" that will be readily accepted and understood will be difficult." ${ }^{\text {348 }}$ Even if the FDA adheres to its view that the opportunity to define "natural" ex ante has been lost, ${ }^{349}$ the agency could ban the use of this term as a "representation" that may render a label misleading.

One way to do so would be to codify the FDA's enforcement policy as a prohibition on the use of the "natural" label for products containing any added colors, artificial flavors, or synthetic substances. The FDA's enforcement actions indicate a strict application of this policy-but enforcement actions have been few in number. Given the enormous number of products labeled as "natural," enforcement by warning letter can only be described as rare and selective. ${ }^{350}$ The FDA's willingness to enforce the policy in isolated cases suggests that the promulgation of a generally applicable regulation embodying the FDA's enforcement policy would help level the playing field in the highly competitive processed food industry. ${ }^{351}$

Promulgating a regulation codifying the FDA's long-held enforcement policy should be easy. It avoids the need to define the term so as to specify all the circumstances under which a product may be considered to be "natural." It takes an ascertainable fact - the presence in a food of added colors, artificial flavors, or synthetic substances - and makes clear that the use of the term "natural" on labeling of such products constitutes misbranding.

This step does not require any assessment of the safety of the additive or the likely health effects of the product. ${ }^{352}$ Additives may be "safe" for human consumption, at least in certain amounts, even though they are not naturally occurring substances. Thus, the fact that an additive is SRAS or that its use is

Terms, 56 Fed. Reg. 60,421, 60,466-67 (proposed Nov. 27, 1991).

348. Id.

349. Id.

350. This is not to say enforcement is selectively targeted. But action has been taken against only a minuscule percentage of products labeled as "natural" but containing artificial or synthetic substances. The author found only four or five warning letters relating to "natural" claims on the FDA's website for the past several years. See generally Warning Letters, FoOD \& DRUG ADMIN., http://www.fda.gov/ICECI/EnforcementActions/WarningLetters/default.htm [http://perma.cc/A75M-KQAU] (last updated Nov. 18, 2015).

351. Cf. NegOwETTI, supra note 7. But note that the FDCA's available sanctions are limited in the case of misbranding based on misleading representations. See 21 U.S.C. § 333(d) (2012) (limiting imposition of penalties on a person who has violated the FDCA "if the violation exists solely because the food is misbranded under [21 U.S.C. $\S 343(\mathrm{a})(2)]$ because of its advertising).

352. The FDA's 2015 announcement states that the agency "did not consider," in establishing its 1991 policy, "whether the term 'natural' should describe any nutritional or other health benefit." Use of the Term 'Natural' in the Labeling of Human Food Products; Request for Information and Comments, 80 Fed. Reg. 69,905, 69,906 (Nov. 12, 2015). The FDA now seeks public comment on that issue. Id. at 69,908 . 
permitted by an existing food additive regulation is irrelevant to the question of "natural" labeling. Likewise, products containing additives may be "healthy," at least for some consumers or in comparison to other products. Health and nutrient content claims are regulated separately; ${ }^{353}$ there is no overlap with the regulation of "natural" claims. ${ }^{354}$ The fact that a product may be "safe" or "healthy" does not make it natural.

\section{Commercial Speech Jurisprudence Should Provide no Obstacle}

The FDA's reluctance to define the term "natural" likely stems in part from its understanding of the way protection of commercial free speech relates to food labeling. ${ }^{355}$ This concern should provide no obstacle to prohibiting the use of the term "natural" on products containing non-naturally occurring food additives. Under the Central Hudson test for assessing restrictions on commercial speech, the government's burden to justify its restriction on speech (under a balancing test) arises only after it is determined that the speech in question concerns lawful activity and is not misleading. ${ }^{356}$ Acknowledging that commercial speech is protected, the Court there stated:

The First Amendment's concern for commercial speech is based on the informational function of advertising... Consequently, there can be no constitutional objection to the suppression of commercial messages that do not accurately inform the public about lawful activity. The government may ban forms of communication more likely to deceive the public than to inform it ... If the communication is neither misleading nor related to unlawful activity, the government's power is more circumscribed. The State must assert a substantial interest to be achieved by restrictions on commercial speech. Moreover, the regulatory technique must be in proportion to that interest. ${ }^{357}$

As the FDA's enforcement policy and practices indicate, using the term "natural" on the label of a product containing artificial or synthetic additives misleads consumers who would not normally understand such substances to be "natural" or to be found in food. Because the use of the term "natural" in connection with

353. See 21 U.S.C. § 343(r).

354. See generally NEGOWETTI, supra note 7, at 3-7.

355. See generally Marion Nestle, How About Reassessing First Amendment "Right" to Market Junk Foods, Food PoL. (Dec. 7, 2010), http://www.foodpolitics.com/2010/12/how-aboutreassessing-first-amendment-right-to-market-junk-foods/ [http://perma.cc/US3Q-4GCM] (summarizing various positions in debate); see also Robert Lustig \& Marsha Cohen, FDA Must Define, and Enforce, the Term "Natural," N.Y. Times (Nov. 11, 2014, 6:19 PM), http://www. nytimes.com/roomfordebate/2014/11/10/should-the-fda-regulate-the-use-of-natural-on-foodproducts-15/fda-must-define-and-enforce-the-term-natural [http://perma.cc/2NRB-C2CY].

356. Cent. Hudson Gas \& Elec. Corp. v. Pub. Serv. Comm'n, 447 U.S. 557, 566 (1980) (emphasis added).

357. Id. at 563-64 (emphasis added) (citations omitted). 
food products containing artificial or synthetic substances is misleading, the balancing test under which regulations often fail is not applicable.

It is true that the Court recently appeared to adopt an even more stringent test for restrictions on commercial speech by asking a threshold question: is the speech in question content-based ? $^{358}$ The proposed ban on use of the term "natural" on the label of any product containing artificial or synthetic substances is content-based. The Court has not addressed Sorrell's application to food labeling. In a different context arising under the FDCA, lower federal courts appear to be split on the question of the scope of the misbranding provision as it applies to misleading claims regarding off-label uses of FDA-approved drugs. In a 2012 case, the Second Circuit applied Sorrell to invalidate the FDA's ban. ${ }^{359}$ In Caronia, the defendant was being prosecuted for selling drugs that the FDA alleged to be misbranded by virtue of promoting off-label use. ${ }^{360}$ The Caronia majority noted as important the fact that the FDCA itself does not expressly prohibit or criminalize off-label promotion. ${ }^{361}$ More recently, a federal district court declined to follow Caronia. ${ }^{362}$ The FDA's refusal to date to define the term "natural" or regulate its use might present a similar problem for this Article's proposal, effectively calling into question the FDA's authority to regulate "natural" claims under the misbranding provision. The FDA's recent indication that it may yet regulate "natural" labeling should help to dispel this concern.

Moreover, the Supreme Court in Sorrell neither disavowed Central Hudson nor stated anything to indicate that this new threshold question is to be asked before determining whether or not the commercial speech is misleading. ${ }^{363}$ Discussing drug regulation under the FDCA in Caronia, Judge Livingston stated:

That the FDCA is both "content- and speaker-based" within the meaning of Sorrell does not alter the foregoing analysis. Every commercial speech case, by its very nature, involves both content- and speaker-based speech restrictions. Yet the Supreme Court has long acknowledged - and acknowledged again in Sorrell - that "the government's legitimate interest in protecting consumers from commercial harms explains why commercial speech can be subject to greater governmental regulation than noncommercial speech." Indeed, the Supreme Court struck down the ban on energy advertising in Central Hudson because a contentbased less-restrictive alternative existed. Sorrell did not purport to

358. Sorrell v. IMS Health Inc., 131 S. Ct. 2653, 2667-68 (2011) (involving restrictions on the sale of information in a speaker's possession and noting that "[i]n the ordinary case it is all but dispositive to conclude that a law is content-based").

359. United States v. Caronia, 703 F.3d 149, 154 (2d Cir. 2012) (noting fact that the FDCA itself does not expressly prohibit or criminalize off-label promotion).

360. Id. at 157.

361. Id. at 162 .

362. See, e.g., Jones v. Medtronic, 89 F. Supp. 3d 1035, 1047 n.16-17 (D. Ariz. 2015) (declining to follow Caronia and citing cases on both sides).

363. Caronia, 703 F.3d at 180-81 (Livingston, J., dissenting). 
overrule the Central Hudson test, which has guided First Amendment doctrine in this area for thirty years.

Moreover . . Congress intended the FDA approval process to prevent dangerous products with false or misleading labels from entering the market, and also to provide a base of reliable, objective information about prescription drugs that could help physicians and patients identify potentially misleading claims. Clearly this is the type of statute to which Sorrell intended that Central Hudson would still apply ...

Our system of drug regulation developed to protect consumers from misleading and unsubstantiated claims about drugs' safety and efficacy, and the prohibition on off-label promotion by drug manufacturers is essential to maintaining the effectiveness of that system. Therefore, even if such a prohibition is considered a direct regulation of speech, it is a regulation that directly advances a substantial government interest in a manner not more extensive than necessary to serve that interest. I would thus find it constitutional under Central Hudson and Sorrell. ${ }^{364}$

On the understanding that misleading commercial speech remains subject to regulation for the reasons articulated in Central Hudson, the fact that the proposed ban on a particular use of the term "natural" is content-based presents no obstacle to the FDA's regulation of "natural" labeling of products containing food additives.

In short, the existing statute authorizes the FDA to regulate misleading representations on food labels. FDA policy has long regarded the presence of added colors, artificial flavors, or synthetic substances as inconsistent with labeling the food as "natural." Because this use of the "natural" claim is misleading, its use renders products containing additives misbranded and makes it unlawful to sell them in interstate commerce. The First Amendment's protection of commercial speech applies only to representations that are not misleading. Thus, the FDA should prohibit the use of the term "natural" on the labels of food products containing artificial and synthetic substances.

\section{CONCLUSION}

Congress recognized the dangers inherent in a food supply becoming dominated by industrially-produced, highly processed foods that tend to be full of novel, artificial additives. It enacted a regime requiring strict oversight of the food additives it deemed, as a class, to be unsafe. But it also wanted to foster innovation in the food industry to achieve the convenience and low cost consumers demanded. The result was the "GRAS loophole." This loophole, along with the FDA's broad responsibilities and limited resources, has created a result Congress never intended: most food products reach the market without any FDA review of safety. Worse yet, the FDA lacks comprehensive information about

364. Id. (internal citations and footnotes omitted). 
additives actually in use.

This Article proposes modest changes to bolster oversight of additives. First, key terms should be defined to restore the distinction in regulatory treatment between food and additives. Second, producers should be required to notify the FDA of all additives and to monitor their safety on an ongoing basis. Producers must also report to the FDA credible new evidence raising safety concerns so that the FDA can take action to protect consumers when warranted. Finally, the FDA should adopt a regulation prohibiting the use of the term "natural" on the label of any food product containing food additives on the ground that such a claim is inherently misleading. These proposals do not entirely restore the strict oversight called for in the 1958 Act. But taken together, they may partially fill the regulatory vacuum that exists today with respect to food additives. 